\title{
The impact of new manufacturing requirements on production line productivity and quality at a focused factory
}

\author{
Ashok Mukherjee ${ }^{\mathrm{a}, *}$, Will Mitchell ${ }^{\mathrm{b}}, \mathrm{F}$. Brian Talbot ${ }^{\mathrm{c}}$ \\ ${ }^{a}$ WSOM, Case Western Reserve University, 10900, Euclid Avenue, Cleveland, OH 44106-7235, USA \\ ${ }^{\mathrm{b}}$ University of Michigan Business School, MI, USA \\ ${ }^{\mathrm{c}}$ University of Michigan Business School, MI, USA
}

Received 2 October 1998; accepted 17 June 1999

\begin{abstract}
This research studies how changes in manufacturing requirements affect production line performance in a focused factory. Specifically, we examine whether production line labor productivity and conformance quality decline as the range of models produced and the heterogeneity of production volume increase in a factory designed for high volume production of a narrow range of models. We use the organizational nature of production lines to argue that the performance of focused production lines will decline when the lines adopt new manufacturing tasks that are outside the scope of the absorptive capacity developed through the execution of their prior focused manufacturing task, but not otherwise. The study examines four years of data from 16 production lines of a compressor manufacturing factory of the Copeland Corporation. Our statistical analysis identifies limits to change, suggests paths to successfully changing the manufacturing requirements of a focused factory, and places the operations strategy discussion of focused factories in a dynamic environment. (C) 2000 Elsevier Science B.V. All rights reserved.
\end{abstract}

PACS: M11

Keywords: Operations strategy; Focused factory; Organizational change; Field research

\section{Introduction}

In the Operations Management literature, the argument that focused factories should typically outperform more general-purpose production facilities started with the seminal work of Skinner (1974) and continues to date (Schmenner and Swink, 1998). Although most of the writing on manufacturing focus emphasizes stable manufacturing environments

\footnotetext{
* Corresponding author. i2 Technologies, Irving, TX, USA. Tel.: +1-214-860-600; e-mail: ashok_mukherjee@i2.com
}

(Stobaugh and Telesio, 1983; Hayes and Wheelwright, 1984, p. 90, p. 108; Hayes and Clark, 1985; Hill, 1994, p. 152), most factories inevitably face changes in their manufacturing requirements. Owing to difficulties in adaptation, it is possible that the performance of focused factories will decline when their activities change. This paper examines the relationship between manufacturing focus and factory performance in a dynamic environment. Specifically, we examine how the performance of a focused factory's production lines changes after the factory changes its manufacturing requirements. We define focus in terms of manufacturing requirements and 
measure changes in focus through variables that affect production line activities.

Our explanations of relationships between change in manufacturing requirements and production line performance draw from a conceptual model of manufacturing activities that includes two dimensions: manufacturing routines and absorptive capacity for adaptation of routines. We base the model on the organizational nature of production line activities. A production line is an organizational unit, which one can view as a collection of self-sustaining routines (Nelson and Winter, 1982). Organizations and their sub-units such as production lines often find it difficult to depart from prevailing routines. We draw most directly on the concept of absorptive capacity, which is the ability to recognize, evaluate, assimilate, and utilize new knowledge (Cohen and Levinthal, 1990). We argue that manufacturing focus sometimes creates conditions under which production lines lack the absorptive capacity to adapt effectively to requirements unrelated to their existing focused task. We conceptualize manufacturing tasks as activities that the manufacturing function needs to accomplish. We hypothesize that the performance of focused production lines will decline when the lines adopt new manufacturing requirements that are outside the scope of the absorptive capacity developed through the execution of their prior focused manufacturing requirement.

We test the hypotheses at 16 production lines of a well-known focused factory of the Copeland Corporation of Sidney, Ohio, using primary output and performance data over a four-year period during which the company changed the manufacturing requirements of the production lines. The factory is located at Hartselle, AL. Consistent with the requirements of a theory testing case study, the conceptual variables of the hypotheses are general constructs, while the operational variables are specific to the site. Our statistical analysis both illustrates the limits of change in operations strategy and identifies paths through which factories may undertake successful change.

\section{Background literature}

Studies seeking empirical evidence on the benefits and costs of factory focus include case studies and statistical studies. Several broad, multi-industry, multi-plant case studies (Skinner, 1974, Ferdows, 1997) as well as narrower-scope site-specific studies (Hayes and Wheelwright, 1984, p. 34, Ruwe and Skinner, 1987) suggest that focused factories lead to better manufacturing performance and competitive success. In the practitioner literature, studies by consulting firms such as McKinsey (Rommel et al., 1995), and Andersen Consulting (Harmon, 1992) report substantial improvement of operating performance of factories through implementation of focus at over 2000 factories worldwide. However, while case studies examining specific focusing efforts often suggest superior factory performance, the conclusions often come from broad observations rather than scientific examinations.

In addition, a few statistical studies have studied how product variety, which is one surrogate of focus, affects manufacturing performance, producing ambiguous results. Some researchers have observed positive relationships between manufacturing performance and measures of limited product variety, both cross-sectionally (Banker et al., 1990; Brush and Karnani, 1996; McDuffie et al., 1996) and longitudinally (Anderson, 1995). Other researchers have found little effect of product variety on manufacturing performance (Hayes and Clark, 1985; Foster and Gupta, 1990; Kekre and Srinivasan, 1990). Thus, it is difficult to arrive at a generalizable empirical conclusion about the relationship between product variety and performance from prior studies. More importantly for our purpose, however, most of these examinations do not address whether the manufacturing plants they studied engaged in the managerial exercise of focusing, which involves determining limited manufacturing requirements and tailoring the manufacturing systems to these requirements. Moreover, the studies differ in the variables they have used as measures of performance and product variety. Studies that use relatively simple measures of product variety find little correlation between variety and cost (e.g., Hayes and Clark, 1985; Foster and Gupta, 1990; Kekre and Srinivasan, 1990), while studies using more sophisticated measures of product variety often find a positive relationship between limited variety and superior performance (e.g., Banker et al., 1990; Anderson, 1995; McDuffie et al., 1996). This speaks to the need for careful consideration of the 
metrics of focus. We believe that our work facilitates the measurement of aspects of the complex phenomenon of focus. Finally, theoretical economic models have been unable to include the number of products in the cluster of complementary elements that maximize the profits of most modern manufacturing firms (e.g., Milgrom and Roberts, 1990). Therefore, substantial room remains for additional research.

We use an approach, involving the production line as the unit of analysis, that we believe can be applied in many discrete manufacturing industries. Our study explicitly considers the nature of focusing at production lines, and then rigorously examines the impact of changing two dimensions of production line focus. In contrast to the above-mentioned quantitative studies that examine aspects of product variety, which represents only one dimension of the complex phenomenon of focus, some recent studies have begun to measure focus as a multi-dimensional concept, using perceptual data (Bozarth, 1993; Pesch and Schroeder, 1996; Berry and Bozarth, 1997). We discuss these studies in detail in Section 5.2 where we measure manufacturing requirements, and position our work relative to the conceptual frameworks that these authors suggest. In the next section of the paper, we present a conceptual model of factory focus that we hope will help clarify the discussion of manufacturing focus in the literature and facilitate empirical research.

\section{Conceptual model of factory focus}

We propose a conceptual model of manufacturing activities that includes two key dimensions: manufacturing routines and absorptive capacity for adaptation of routines. The model suggests two propositions concerning adaptation to changed manufacturing requirements. Fig. 1 portrays the model and propositions.

\subsection{Limited-variation manufacturing routines}

We start by discussing the role of manufacturing routines in a focused factory strategy. In our approach, as Fig. 1 highlights, a factory that has chosen to adopt focused manufacturing requirements will develop a set of manufacturing routines that involve a limited skill set for its production lines. One can define the manufacturing task of a factory as devel-

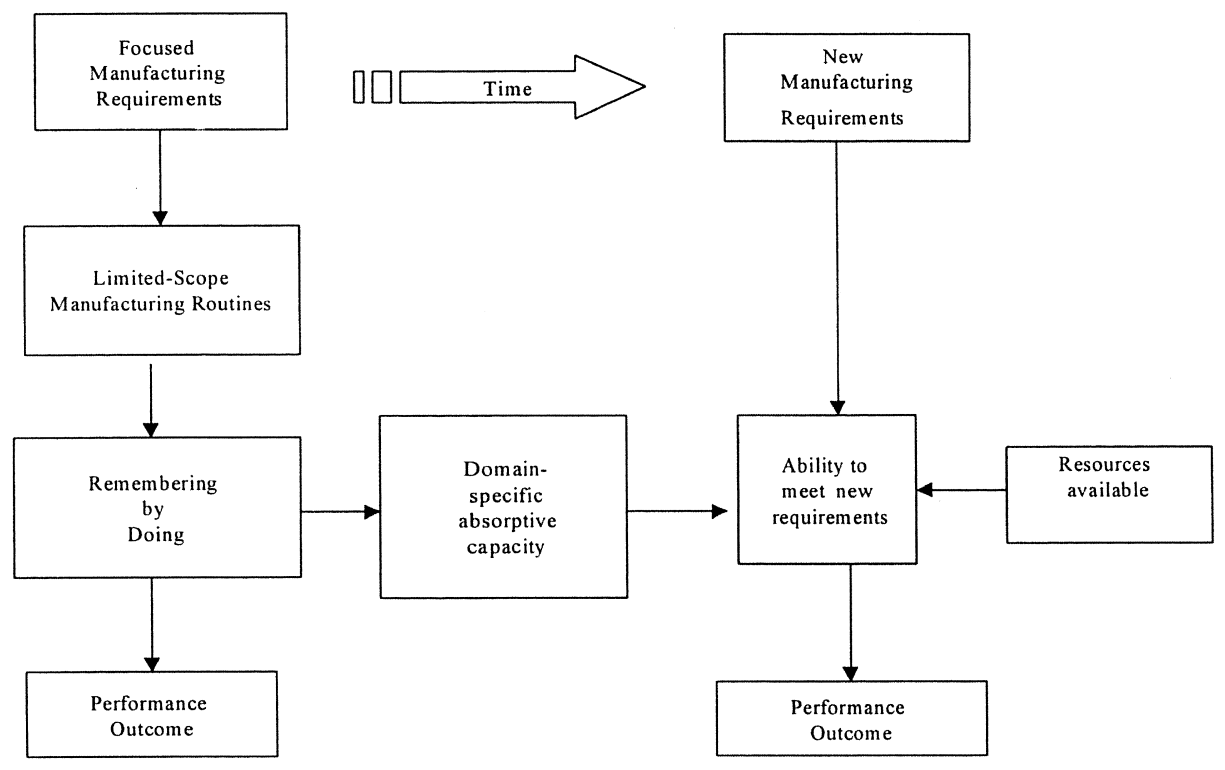

Fig. 1. Conceptual model and propositions. 
oping and exploiting a set of manufacturing skills deemed necessary by the firm's strategy. We can think of the manufacturing skills as manifestations of the corporate core competencies (Prahalad and Hamel, 1990) that are resources of the firm (Wernerfelt, 1984). Indeed, Prahalad and Hamel argue that organizational learning about how to coordinate diverse production skills is a key element of core competence. The skill-based view of manufacturing tasks has the appealing characteristic that it provides a theoretical basis for defining focus, because the view connects closely with the evolutionary theory of Nelson and Winter (1982). A firm's manufacturing skills are one component of the firm's skills. Similarly, the manufacturing skills of a factory comprise the skills of the production lines and related support functions. Following Nelson and Winter's view that routines are the skills of an organization, we equate skills of a production line with the routines executed at the line. Examples of routines at a production line include technological processing, information flow, material flow, and manufacturing support routines. The general description of routine performance of a production line in equilibrium contains two elements. First, the line must retain in its repertoire all routines the line invokes in the given state of operation. Second, the operators of the line must be able to receive, interpret, and respond to messages by executing appropriate routines at appropriate times.

A key concept underlying the idea that routines are the skills of an organization is that organizations remember by doing. Thus, firms remember production line skills through executing them. The execution of a production line routine involves the effective integration of a number of component subroutines often accomplished without conscious overview, that is, without requiring the explicit attention of management. Since the purpose of focus is to excel in a skill, and since skills are combinations of routines that production lines remember by doing, achieving focus in the task of a production line requires that the line execute the task repetitively. Major tasks for management in focusing a production line include designing a set of routines that are coherent components of a specific targeted skill set and establishing a process in which employees, machines, and systems can repeat the routines without a need for explicit reconsideration each time the line executes a step. Hence, a focused manufacturing facility will limit the number of manufacturing routines the facility requires of its operators. In general, the fewer the routines, the more focused a facility. In turn, the performance that the factory achieves is an outcome of the strength of its routines, in the context of its relevant competitive environment. As we discussed earlier, there is at least partial empirical evidence that firms that adopt more focused approaches often achieve superior performance.

A firm can limit the number and variety of routines at a factory's production lines by limiting the demands on the factory itself. In the late 1970s to mid 1980s, various opinions emerged about how to limit the demands on a factory. Table 1 illustrates several options, drawing from published empirical and conceptual work (Hayes and Schmenner, 1979; Schmenner, 1982, Hayes and Wheelwright, 1984, pp. 90-108, Hill, 1989, p. 102). The table's classification system for focusing factories examines the firm's portfolio along one of a set of alternative dimensions and then assigns sections of the portfolio to separate factories. We note six focusing dimensions, including product, process, market/customer segment, geographic market region, volumes, and suppliers. However, factories with limited portfolios along a particular dimension may contain conflicts within other dimensions. For example, along the market segment dimension, a product-focused factory may serve several markets that have different price expectations, regulatory standards, and delivery requirements. Consequently, potentially conflicting routines may exist even within a seemingly wellfocused facility.

We can analyze the conflicts that arise along focusing dimensions by treating the dimensions of focus as complementary at the level of the individual factory. We draw from Wheelwright (1979) and a Delphi survey of an expert panel by Pesch (1996) to suggest that, at the factory level, focus involves limiting the operating routines of the factory on a continuum along each of a set of complementary dimensions. For the sake of brevity, we illustrate this concept later using our empirical site as an example in Section 4.2 (Fig. 2). The focusing dimensions assist manufacturing managers only if they know the specific levers that affect change along each dimen- 
Table 1

Dimensions of factory focus

\begin{tabular}{|c|c|c|}
\hline Focusing dimensions & Description & Examples \\
\hline Product & $\begin{array}{l}\text { Products assigned to plants using product based criteria, } \\
\text { including product life cycle }\end{array}$ & $\begin{array}{l}\text { Appliances } \\
\text { Consumer electricals } \\
\text { Canned food } \\
\text { Medical instrument }\end{array}$ \\
\hline Process & $\begin{array}{l}\text { Segments of the production process assigned to different } \\
\text { plants based on process based criteria }\end{array}$ & $\begin{array}{l}\text { Automobiles } \\
\text { Consumer electronics } \\
\text { Heavy chemicals } \\
\text { Rubber products } \\
\text { Apparel }\end{array}$ \\
\hline Market/Customer Segments & Plants dedicated to specific market(s) or customer(s) & $\begin{array}{l}\text { Beverage bottling } \\
\text { Industrial equipment } \\
\text { Industrial gas }\end{array}$ \\
\hline Geographic Market Region & Each plant produces for a specified geographic region & $\begin{array}{l}\text { Energy generation } \\
\text { Printing } \\
\text { Glass } \\
\text { Asphalt/concrete }\end{array}$ \\
\hline Volume & High, low and medium volume products assigned to different plants & $\begin{array}{l}\text { Industrial equipment } \\
\text { Consumer durable }\end{array}$ \\
\hline Suppliers & Each plant procures from a specified geographic region & $\begin{array}{l}\text { Paper and pulp } \\
\text { Lumber } \\
\text { Meat processing } \\
\text { Agricultural products } \\
\text { Mineral processing }\end{array}$ \\
\hline
\end{tabular}

sion. We call these levers the 'controlling determinants' of focus. As we have noted in our review of the literature, controlling determinants are likely to be case-specific.

The factory-level decisions firms make along the focusing dimensions affect the demands placed on the routines of production lines and may determine the scope of the task of these lines. For instance, a decision to offer three rather than two types of engine for an automobile may increase the demand on the drive-train lines of an assembly plant by requiring additional material, information, and coordination. The manner in which dimensional variations at the higher levels affect the demands on a production line remains an open research issue. We attempt to gain insight into this issue by examining the case of a focused factory.

The discussion of routines highlights the role of self-sustaining manufacturing routines in achieving the production line skill of a focused factory. We stress the need to limit variation along multiple focusing dimensions. We now look at the second major element of the model of manufacturing activi- ties, which is routine-specific absorptive capacity for adaptation.

\subsection{Routine-specific absorptive capacity}

We have argued that focused factories achieve highly effective activities by creating, using and reinforcing a limited set of self-sustaining routines in their production lines. Over time, in a relatively stable environment, this can result in outstanding performance. However, most focused factories eventually will face a need to change their activities when changes in the competitive environment raise demands for new manufacturing requirements. In part, the ability of the firm to develop new routines that suit the new manufacturing requirements will depend on the financial and intellectual resources that are available to the firm. In addition, the self-sustaining nature of routine operations may constrain the ability of organizational units to change their activities to adapt to new manufacturing requirements, independent of available resources. The degree of this diffi- 


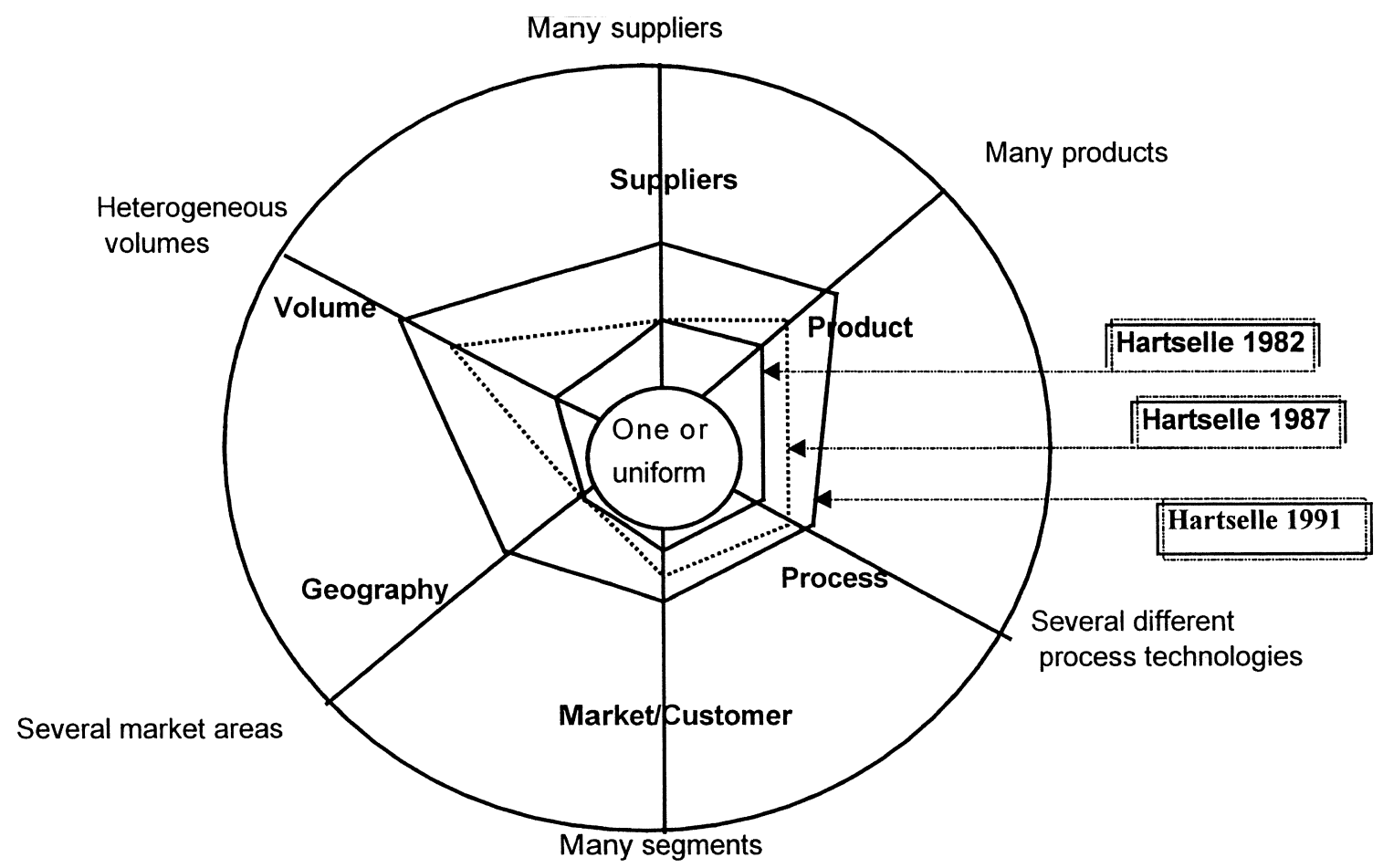

Fig. 2. Evolution of focus at Copeland Hartselle.

culty often depends on how related the new requirements are to the old requirements of the unit. The ability to meet a new requirement may require unlearning, learning and responding in a new knowledge domain. This requires an ability to evaluate and utilize new knowledge, which Cohen and Levinthal (1990) call absorptive capacity. Fig. 1 uses the term routine-specific absorptive capacity to refer to the limits that a particular set of prior routines places on the ability of a production line to learn new skills.

While prior research has not used the concept of absorptive capacity at the level of the production line, studies at levels of analysis both below and above the production line level use the concept. Cohen and Levinthal (1990) base their argument on the literature in individual learning, and establish absorptive capacity largely as a function of prior related knowledge. Specific to manufacturing firms, Abernathy (1978) and Rosenberg (1982) have noted that direct manufacturing experience helps a firm to recognize and utilize new information relevant to a specific product-market. We believe that the argu- ment concerning individual-level and firm-level absorptive capacity also applies at the production line level. For our purpose, new knowledge refers to a shared understanding of the change in manufacturing requirements and the consequent responses that a production line will need to undertake in order to create routines that meet the new requirements. Thus, a production line needs to recognize the new requirements in terms of the routines that they will need, evaluate the line's own repertoire of routines in order to identify potential recombination elements, identify external resources that the new routines will require, and then utilize appropriate existing elements together with external resources to form a response.

Absorptive capacity has both inward and outward elements. In part, the absorptive capacity of a production line develops through cumulative transfer of knowledge among the members of a line, which is the inward component. In addition, the absorptive capacity develops through the interface of the line with its environment, which is the outward component. The environment includes other lines and func- 
tions within the factory, as well as external agents such as parts suppliers. However, there may be a trade-off between the efficiency of internal communication within the line and the ability of the line to assimilate and exploit information from outward sources. Focusing a production line will often stress the inward component at the expense of the outward one, consistent with the argument of Arrow (1974) that the efficiency of an internal communication process is one of the reasons firms are economically attractive forms of organization.

A line's manufacturing routines will tend to shape the line's adaptability. As a by-product of routine activity, a production line will tend to develop absorptive capacity for new knowledge that relates closely to the current set of skills. For new knowledge that differs markedly from current skills, on the other hand, production lines must develop new absorptive capacity to be successful. Because absorptive capacity builds on past activities, however, developing new absorptive capacity will often be slow and difficult. Therefore, pursuit of a narrow focus in one period may constrain the ability to create absorptive capacity unrelated to the initial focus, so that the existing limited-variation routines of a focused production line constrain the line's ability to meet new manufacturing requirements.

\subsection{Propositions}

The conceptual model of factory focus suggests core propositions concerning production line performance following the introduction of new manufacturing requirements. We have defined production line focus as repeated executions of a limited number of routines that the production line remembers by doing. Highly focused factories will tend to have production line routines that are consistent with the specific skills that the factory requires in its competitive environment. Management can limit the set of skills that a factory requires and the set of routines that a production line executes by limiting the operating range of the relevant controlling determinants along the complementary focusing dimensions. In turn, the limited set of routines will limit the capacity that the line develops to absorb new knowledge. The introduction of new manufacturing requirements may necessitate that production lines learn new routines, while the existing absorptive capacity will shape the effectiveness of the new routines. Thus, the strategic action of focusing production lines may limit the ability of the lines to respond effectively to new manufacturing requirements, because the lines' limited-variation manufacturing routines will shape the development of absorptive capacity for new knowledge. Correspondingly, the performance of the production lines following the adoption of new requirements will tend to vary, depending on the fit between a line's absorptive capacity and the demands of the new requirements. At this point, we will refer to production line performance as a general concept. In the empirical section, we will study both line efficiency and line quality.

Proposition 1: The performance of focused production lines will decline when the lines adopt new routines that are outside the scope of the absorptive capacity the lines developed in order to meet their prior manufacturing requirements.

Proposition 2: The performance of focused production lines will not decline when the lines adopt new routines that are within the scope of the absorptive capacity the lines developed in order to meet their prior manufacturing requirements.

These general propositions are the basis of the specific hypotheses that we test using data from the Hartselle focused factory. The next section describes the methodology and the empirical context of our study. The following section develops the hypotheses.

\section{Research methodology and empirical site}

This section first discusses our adoption of a single-site field-study as the appropriate methodology for our research objectives. We then discuss the evolution of focus at the site where we conducted the study.

\subsection{Single-site field study}

Empirical research on focused manufacturing faces problems with the basic tenets of definition as prescribed for socio-technical research (Lachenmeyer, 1971). These difficulties mirror those faced in similar efforts in other fields, as discussed by social-science scholars such as Verba (1976) and 
Campbell (1975). Such difficulties have led researchers in several fields to recognize the importance of single cases as a desirable research method in such situations (Naroll, 1962; Lasswell, 1968; Becker, 1970; Russet, 1970).

Given the lack of a universally understood definition and measurement of factory focus, an interpretive case perspective is appropriate for our study. First, large sample research based on perception of object reality assumes uniformity and reliability of secondary source knowledge. The practitioner literature demonstrates the potential fallacy of that assumption regarding focused manufacturing (e.g., Harmon, 1992; Rommel et al., 1995). Consequently, primary source methods are appropriate in the study of factory focus, consistent with long-standing views concerning the relevance of single-site field studies (Donham, 1922; Lijphart, 1971, 1975). Second, context dependence of an object or behavior in large sample studies may result in inferences that are either simplistic or tautological (Campbell, 1975; Cronbach, 1975). For Operations Management research, Hill et al. (1987) note such limitations of the large sample perspective. Finally, large sample research tends to increase reliability but may reduce the validity of the results (Emory, 1985, pp. 94-98), an unavoidable roadblock in studying this topic. Interpretive research, on the other hand, can successfully investigate specific phenomenon through in-depth studies.

We view this case study as a theory testing case study, following the typology of Yin (1984), since this research generates its propositions from theory and then empirically tests them. We fulfil the critical requirement for a single-site study, because we formulate the explanations for the case in terms of general rather than idiographic variables (Eckstein, 1975; George, 1979). Further, because our units of analysis are production lines within a factory, the availability of several units within one case serves the research objective by allowing us to study several outcomes within a constrained case. We followed guidelines for theoretical site-selection by George (1979) and Eisenhardt (1989). Through a survey of the literature and subsequent dialogue with company management through meetings and unstructured interviews, we selected the flagship factory of the Copeland Corporation at Hartselle, AL as the study site. We selected the site due to its experience with a successful focus and because it underwent a subsequent defocusing. ${ }^{1}$

\subsection{Evolution of focus at Copeland Hartselle}

In 1979, Copeland established its 256,000 square feet flagship factory at Hartselle, AL at a cost of US\$30 million to manufacture one million units annually of a new, high-efficiency, 'CR' model refrigerant compressor. The company decided to serve the market with a few compressor models, assembled from multiple combinations of a few parts, produced in large batch sizes, using a minimum of factory complexity.

\subsubsection{Initial focus: $1979-1985$}

Copeland divided the facility into two areas, machining and assembly. Machining carried out metal removal processes such as milling, turning, drilling, and grinding. The machine shop was the center of focus in its consumption of planning efforts and investment. The shop had seven machining lines, which we designate as ML1 (Machining Line 1) through ML7, with one line, ML3, having two subordinate lines designated ML3a and ML3b. The manufacturing task of this shop was to excel in high volume, high precision machining of a narrow mix of components, with the goal of attaining the world's best cost position. The plant implemented this focus successfully and the machine shop became a showpiece for the company in the early 1980s.

The assembly lines assembled machined and purchased parts to form a complete compressor. The operations comprise several fastening, fitting, welding, and brazing processes. Out of a total of eight assembly lines, four lines built sub-assemblies, which we designate as AL1 (Assembly Line 1), AL2, AL3, and AL4. The other four lines are main assembly lines, which we designate as AL5, AL6, AL7 and AL8. The manufacturing task of the assembly shop

\footnotetext{
${ }^{1}$ Our primary sources of information on the Copeland Hartselle facility include Copeland internal reports, documents, archives, and interviews with several Copeland managers between 1991 and '94. In addition, we collected information from public sources including HBS Case \# 9-686-088 and HBS Film \# 9-887-527.
} 
was to build end-product variety through multiple combinations of the relatively few basic components. Accordingly, the assembly lines had much lower set-up times and many more manual operations compared to the machine shop lines.

Consistent with the dimensions of focus that we summarized in Table 1, we depict the complementary nature of the choices through the multidimensional focus map of Fig. 2. Along each dimension of Fig. 2, a point closer to the center represents greater uniformity of demands. The chosen response vectors of a factory describe the extent of focus at the factory. Hartselle, in its initial years, was a tightly focused factory, as shown in the interior line of Fig. 2. The factory and, in particular, the machine shop as the center of focus, had positions close to the center of the figure along all dimensions. The plant produced a narrow part mix. On the process dimension, Hartselle chose not to manufacture several parts that required a manufacturing technology other than high precision machining. The factory produced its machined components only in high volumes. The factory also had tight focus along the customer and geographic dimensions. The factory served only a few market niches for compressors, namely, domestic air-conditioning and commercial refrigeration, mostly within the continental United States. The factory also developed a limited set of suppliers for its stable set of parts and material requirements. In turn, Copeland management tailored the infrastructural system of the factory to carry out the focused task (Hayes and Wheelwright, 1984, discuss structural and infrastructural systems). Product design modifications made parts amenable to high volume production. The focus on long production runs of high volume, high precision components on dedicated machines also gave rise to specific batching and scheduling guidelines, accompanying off-line quality assurance systems, and specific procedures of other infrastructural elements like maintenance and material handling.

The advantages of Hartselle's initial focus stem from pursuing scale and scope of production, as well as reducing complexity. Relevant benefits due to the scale of production include achieving cost reduction, taking advantage of declining average costs on the high-volume end of a volume-split, and reducing average costs by tailoring the infrastructure to con- centrate on the machining processes. Next, focusing on limited operating ranges including a limited number of products reduced the chances of diseconomies of scope and scale. Finally, lower environmental, technological, and organizational complexity led to reduced coordination costs. With the focused factory fully operating, Copeland transformed itself from an industry follower to the undisputed industry leader.

At the same time, the initial focus at Hartselle created several risks. These risks include avoiding tasks other than cost reduction through the pursuit of scale; experiencing diseconomies of scale due to continued focus on high-volume beyond a certain limit; potential diseconomies of scope if the plant was required to proliferate its product portfolio; curtailing the ability to manage complexity due to the insistence on reducing it; and, a potential lapse of managerial discipline to avoid profitable markets, customers, or geographic regions in order to retain the focus of the factory. These risks created potential performance problems as the manufacturing requirements changed during the second half of the 1980s.

\subsubsection{Change in manufacturing requirements: 1985-1990}

Market pressure for broader product lines and customized modifications coupled with Copeland's aggressive marketing strategy gradually necessitated that the company defocus the Hartselle product line. This study covers a period between 1985 and 1990, when end products proliferated considerably, although the machined components proliferated little. Minor model changes also occurred through the introduction of a new compressor, the CR4. Within the Copeland system, the number of bills of material (BOM) measures product variety. Bills of material for the proliferating end product are designated as '17-digit CR,' a nomenclature system that uses alphanumeric codes. Fig. 3 shows the product proliferation on a monthly basis of the 17-digit CR. Note the relative stability in product-variety over the first 11-month period in contrast to the subsequent periods. Although data concerning the period prior to September 1985 are not available, Copeland managers indicated that the relative stability in productvariety that one observes in the initial data is consistent with the preceding years. 


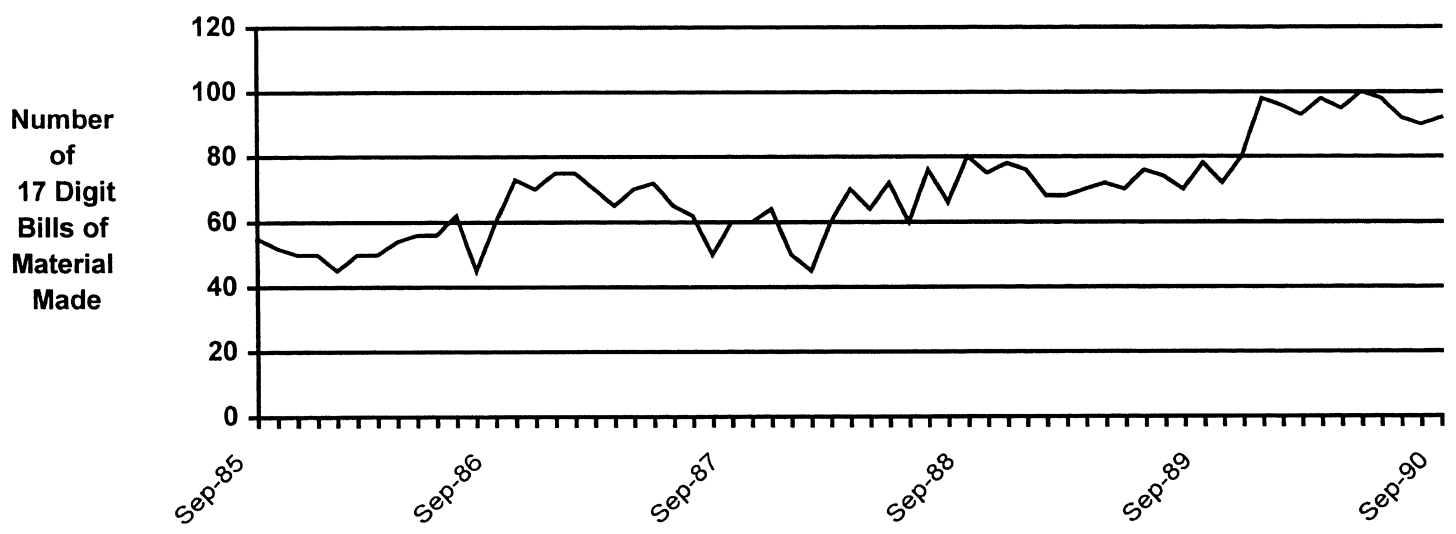

Time in month

Fig. 3. Product proliferation of end product, the 17-Digit CR, 1985-1990.

In addition to the change in the number of products shown in Fig. 3, changes also occurred along other determinants of focus. For example, Table 2 compares the quantities and the number of final product models sold along the "customer type" focusing dimension in 1986 vs. 1991. While detailed data similar to those pertaining to number of products and customer type are not available for each focusing dimension, discussions with management suggest the a focus map as shown in Fig. 2 depicts the evolution of focus at Hartselle over a ten year period, reporting focus positions for 1987 and 1991. Defocusing activities along the dimensions include product proliferation, modification in process technology, expansion of customer base and geographical reach, heterogeneity of production volume, and broadening of the supplier base. This multidimensional perspective on factory focus is important be-

Table 2

CR compressor proliferation at Hartselle, 1986 vs. 1991, by Customer type

\begin{tabular}{lrrll}
\hline Customer type & Quantity & Quantity & Models & Models \\
& \multicolumn{1}{l}{1986} & \multicolumn{1}{l}{1991} & 1986 & 1991 \\
\hline OEM & $1,077,700$ & $1,542,792$ & 272 & 395 \\
Export & 22,745 & 226,003 & 83 & 320 \\
Wholesaler & 68,400 & 96,439 & 46 & 51 \\
Subsidiary & 6459 & 16,449 & 40 & 65 \\
Total domestic & $1,146,100$ & $1,639,231$ & 318 & 446 \\
Total export & 29,204 & 242,452 & 123 & 385 \\
Total & $1,175,304$ & $1,881,683$ & 441 & 831 \\
\hline
\end{tabular}

cause we found that management's initial perception of focus tended to concentrate on the product dimension, consistent with much of the writing in the literature about focus. This emphasis on a single dimension increased the chance that unexpected problems would arise during the defocusing period.

To summarize, the initial meetings with the corporate and plant management showed that the site suited the study, due to its experience with an initial focus and a subsequent defocus. The presence of 16 production lines in two different areas, machining and assembly, provide an opportunity to look for robust inferences.

\section{Research hypotheses}

In this section, we define operational criteria for production line focus and propose empirical hypotheses concerning changes that occur at the production lines of a factory.

\subsection{Production line focus criteria}

We operationalize production line focus in terms of two measures, including heterogeneity of production volumes and number of part numbers. Production line focus is a hierarchical consequence of factory focus. As we noted in Section 3, there usually is not a single way to derive variables at the production line level that correspond to every controlling deter- 
minant at the factory level for every firm in every industry. We use an approach based on the literature and site-relevant criteria that we believe is applicable to many discrete manufacturing environments.

First, we draw upon Pesch and Schroeder (1996) to determine our production line focus criteria. Pesch and Schroeder use five criteria to measure factory focus. The criteria include (1) a clearly defined plant priority; (2) congruence between plant priority and business strategy; (3) consistency of internal decision making within a plant; (4) compatible volume levels among products; and (5) compatible manufacturing requirements among products, where requirements include tolerance, yields, cleanliness, labor skill, and custom specials.

We examine the implications of these criteria of factory focus at the production line level, emphasizing criteria 4 and 5 . We believe that the first two criteria, concerning plant priority and congruence with strategy, are plant-level criteria that do not change cross-sectionally or temporally at production lines of a single plant. We expect that the variation in the third criterion, concerning internal decision making consistency across production lines of the same plant, will be much smaller than the variation in this criterion across plants of different companies, since in the former case, lines will be making decisions within identical boundaries set at the plant level. Further, any change in decision making will likely be unidirectional towards a gradual defocusing (Hayes and Clark, 1985; Hill, 1989, p. 110), and can be represented by the inclusion of a time variable in an empirical model.

We concentrate on the last two criteria that Pesch and Schroeder (1996) use. Corresponding to the fourth criterion, which is compatible volume levels among products of a factory, we use the heterogeneity of part volumes at a production line. Limiting the heterogeneity of volumes is one way to limit the demands placed on a production line. A production line can produce the same number of parts in large, medium, or small volumes. Uniformity of batch sizes may help a production line adopt the economically and technologically appropriate elements such as tooling, jigs and fixtures, material handling systems, production planning and quality control systems, and work routines. Heterogeneity of volumes stretches the designed capabilities of these elements. Two compressor manufacturing plants of Copeland at Alabama and North Carolina exemplify successful focusing of these elements on large only and small only batches respectively (March and Garvin, 1986).

To adopt the fifth dimension of Pesch and Schroeder (1996), we use part mix to measure compatibility in manufacturing requirements among products. This usage is consistent with Pesch and Schroeder's subsequent finding that the 'number of product lines' has a strong, positive and significant correlation with their degree-of-focus score. Further, while the number of products at the factory level provides only limited information about the extent to which these products place different demands on the system, the number of parts on a production line may capture much more adequately the variations placed on the line. A new part on a given line often indicates change of a rather limited nature, mostly on values of design dimensions and processing parameters. For example, on a gear-shaping line producing two gears, the addition of a third part-number will typically indicate another gear that goes through the same shaping operations in the same sequence as the other two, with changes only in process parameter values. Thus, our operationalization of production line focus is consistent with Pesch and Schroeder's characterization of factory focus.

Next, we position our two focus criteria of production volume heterogeneity and number of part numbers by examining the related series of articles by Bozarth (1993), Bozarth and Edwards (1997), and Berry and Bozarth (1997). The series provides three dimensions of focus, including (1) market requirements focus arising out of business strategy or product requirement; (2) manufacturing characteristics focus comprising manufacturing similarity (similarity in production volumes, equipment, labor skills, set up), and organizational autonomy; and (3) congruence between market requirements and manufacturing characteristics. In terms of this framework, we are examining a limited scenario, namely, the impact of certain changes in market requirement focus on production line performance. A factory-level change in a market requirement variable, such as customer or geography, may have several implications at the production line level. Our focus criteria address two line-level implications. The first criterion, part mix, arises as a production line level equivalent for prod- 
uct mix, which Bozarth and Edwards (1997) use as one measure of their market requirements dimension. Our other criterion, volume heterogeneity, reflects a change that occurs at the line level along their manufacturing characteristic dimension. Of the dimensions of manufacturing similarity that this series of articles use, the major changes that arise between different parts that are manufactured on a production line in our study (for example, between three different bearings) are production volumes, rather than equipment, labor skills, or set up.
Table 3 summarizes this discussion. The second column of the table lists several controlling determinants for each focusing dimension that we listed in Table 1. These are similar to what the above-mentioned researchers refer to as 'market requirements' at the factory level. The third column of Table 3 then lists, for each controlling determinant, production line level implications for the two measures of production line focus.

Our intent here is to demonstrate that volume heterogeneity and part mix at the production line

Table 3

Controlling determinants and production line implications of focus at Hartselle

\begin{tabular}{|c|c|c|}
\hline Focusing dimension & Controlling determinant & $\begin{array}{l}\text { Production line implications for part mix and } \\
\text { volume heterogeneity }\end{array}$ \\
\hline Product & $\begin{array}{l}\text { Product-mix width (Kotler, 1994, pp. 434-435) } \\
\text { Product line depth (Kotler, 1994, pp. 434-435) } \\
\text { Product feature variety (McDuffie et al., 1996) } \\
\text { Product attribute variety (Anderson, 1995) } \\
\text { Product customization } \\
\text { Packaging variety } \\
\text { Product-life cycle stages }\end{array}$ & $\begin{array}{l}\text { \# of parts on most lines } \\
\text { \# of parts on most lines } \\
\text { \# of parts on some lines } \\
\text { \# of parts on some lines } \\
\text { \# of parts on some lines } \\
\text { \# of parts on packaging lines } \\
\text { \# of parts on most lines }\end{array}$ \\
\hline Process & $\begin{array}{l}\text { Process life cycle stages } \\
\text { Number of different technologies } \\
\text { Nature of difference in technology } \\
\text { Materials processed }\end{array}$ & $\begin{array}{l}\text { Part numbers, Volume heterogeneity } \\
\text { New parts } \\
- \\
\text { Parts on some lines }\end{array}$ \\
\hline Market/Customer Segments & $\begin{array}{l}\text { Number of customers } \\
\text { Relative size of customers } \\
\text { Product application } \\
\text { Delivery requirements } \\
\text { Inspection requirements } \\
\text { Conformance specifications } \\
\text { Market segments }\end{array}$ & $\begin{array}{l}\text { Likely volume heterogeneity } \\
\text { Likely volume heterogeneity } \\
\text { New part numbers } \\
\text { Volume heterogeneity } \\
\text { Part numbers with specific instructions }{ }^{\text {a }} \\
\text { Part numbers with specific instructions }{ }^{\text {a }} \\
\text { New part numbers }\end{array}$ \\
\hline Geographic Market Region & $\begin{array}{l}\text { Distribution area } \\
\text { Technological standards } \\
\text { Regulatory differences } \\
\text { Delivery requirements } \\
\text { Shipping requirements } \\
\text { Packaging requirements } \\
\text { Lead time }\end{array}$ & $\begin{array}{l}\text { Volume heterogeneity downstream } \\
\text { Additional parts/instructions on some lines }{ }^{\mathrm{a}} \\
\text { Additional parts/instructions on some lines } \\
\text { Volume heterogeneity downstream } \\
\text { Parts/instructions on downstream lines }{ }^{\mathrm{a}} \\
\text { Parts/instructions on downstream lines } \\
\text { Volume heterogeneity downstream }\end{array}$ \\
\hline Volume & $\begin{array}{l}\text { Range of order sizes } \\
\text { Delivery lot sizes for blanket orders } \\
\text { Allowable disruptions of production runs }\end{array}$ & $\begin{array}{l}\text { Volume heterogeneity on most lines } \\
\text { Volume heterogeneity on some lines } \\
\text { Volume heterogeneity on all lines }\end{array}$ \\
\hline Suppliers ${ }^{\mathrm{b}}$ & $\begin{array}{l}\text { Procurement area, number of suppliers } \\
\text { Supplier size range } \\
\text { Incoming inspection requirements and } \\
\text { relationship mode (Shapiro, 1985) }\end{array}$ & $\begin{array}{l}\text { Volume heterogeneity upstream } \\
\text { Volume heterogeneity upstream }\end{array}$ \\
\hline
\end{tabular}

\footnotetext{
${ }^{\mathrm{a}}$ Typically, a factory has its own system to record the instructions in the form of a traceable document (for example, a route sheet, or a standard operating procedure). This document, sometimes based on an alphanumeric extension of the relevant part number, can be counted as a separate part number for our purpose.

${ }^{\mathrm{b}}$ Line level measures capture the supplier aspect of defocusing more weakly than they do for other dimensions. Often, the Materials function takes care of complexities of supplier management, insulating production lines from accompanying variations.
} 
level associate with variations of many controlling determinants of focus at the factory level. Clearly, there may be other variables to control in limiting the demands at the production line level. Nonetheless, although our list is not exhaustive, the measures apply to many manufacturing situations. We believe that the measures are appropriate for this study and many others. Overall, the references cited and the literature in general suggest that part mix and volume heterogeneity are two important dimensions of tracking manufacturing requirements at the production line level.

\subsection{Hypotheses}

We propose two sets of hypotheses that link change of manufacturing requirements with performance of the production lines. We concentrate on the change in requirements from the prior focused period to the new period of defocused requirements, because absorptive capacity is also a function of the prior requirement. To the extent that absorptive capacity is also a function of the recipient, that is, the production line, we include this aspect in our later empirical model building. However, this latter aspect is not what we are examining, and hence, is not a part of the hypotheses.

Copeland designed the machining lines with a focus on excelling in producing a narrow part mix in large volumes. The company designed the assembly and sub-assembly lines with the intent of producing multiple products through multiple combinations of a few components.

In terms of the volumes in which they processed the parts, the machining lines experienced a gradually increasing mix of large and small batch sizes over the period of the study, thereby increasing the heterogeneity of part volumes. At the same time, in assembly, product-variety increased and the volumes in which some of the products were assembled decreased, increasing volume heterogeneity. Given that heterogeneity was a new task for the lines in both shops, we expect that the performance of the lines declines when its focus weakens due to increased the heterogeneity of monthly part-volumes. We propose the following hypotheses for each production line.
H1A: The greater the part volume heterogeneity processed by a machining line or assembly line, the lower the line's performance.

The next hypothesis addresses linkages between production lines. Following the prescription of Skinner (1974), in a focused factory such as Hartselle, the thrust in tailoring is on the configuration of the infrastructural elements to make them consistent with each other and with a system-level deliverable. The span of these elements remains system-wide, across the factory. The production lines of the factory, subject to a common material and information flow and joined by the same infrastructure, may constitute subsystems of a richly joined system (Ashby and Ross, 1960; Simon, 1969; Perrow, 1984). The interesting property of such systems is that interaction between subsystems is stronger than interactions within each subsystem. Consequently, the change of requirement at a line may be either an explicit change at the line or an indirect result of an change at an interrelated line. An explicit change at an assembly line may lead to an indirect change in the demands on a connected upstream machining line, due to greater complexity and variation in component demand. Such an effect is of great interest, because management may mistakenly act as if the task of the machining lines has not changed, since their sets of components remain unchanged. We propose the following hypothesis. ${ }^{2}$

H1B: The greater the part mix breadth processed by an assembly line, the lower the performance of a corresponding upstream machining line.

In terms of part-mix on a given line in the machine shop, while the part mix produced usually changed from month-to-month, it did so within a

\footnotetext{
${ }^{2}$ In this hypothesis concerning upstream performance, we have only included downstream part mix, not downstream volume heterogeneity, as a focus criterion. We would also expect negative relationships with downstream volume heterogeneity. We tested a model with volume heterogeneity of the downstream line as an added variable. We found the expected significant negative influence in about half the cases, and no positive influences. Importantly, the results that we report are robust in the models that include the downstream volume heterogeneity variable. We do not report the models with downstream volume heterogeneity, however, because we believe that there are sufficient correlations and data limits whereby the addition of the variable pushes the data somewhat beyond appropriate limits.
} 
Table 4

Conceptual and operational variables

\begin{tabular}{|c|c|c|c|c|c|}
\hline \multirow[t]{2}{*}{ Hypothesis } & \multicolumn{2}{|l|}{ Dependent variable } & \multicolumn{2}{|l|}{ Independent variable } & \multirow[t]{2}{*}{ Expected relationship } \\
\hline & Conceptual & Operational & Conceptual & Operational & \\
\hline H1A & $\begin{array}{l}\text { Production } \\
\text { line performance }\end{array}$ & $\begin{array}{l}\text { 1. Assembly and machining } \\
\text { line labor productivity } \\
\text { 2. Assembly and machining } \\
\text { line conformance quality }\end{array}$ & $\begin{array}{l}\text { Task change for which } \\
\text { line lacks absorptive capacity }\end{array}$ & $\begin{array}{l}\text { Part volume hetero- } \\
\text { geneity at the line }\end{array}$ & Negative \\
\hline H1B & $\begin{array}{l}\text { Machining } \\
\text { line performance }\end{array}$ & $\begin{array}{l}\text { Machining line labor } \\
\text { productivity }\end{array}$ & $\begin{array}{l}\text { Indirect task change for which } \\
\text { line lacks absorptive } \\
\text { capacity }\end{array}$ & $\begin{array}{l}\text { Part mix breadth at a } \\
\text { downstream assembly line }\end{array}$ & Negative \\
\hline $\mathrm{H} 2 \mathrm{~A}$ & $\begin{array}{l}\text { Production } \\
\text { line performance }\end{array}$ & $\begin{array}{l}\text { 1. Assembly and machining } \\
\text { line labor productivity } \\
\text { 2. Assembly and machining } \\
\text { line conformance quality }\end{array}$ & $\begin{array}{l}\text { Task change for which line has } \\
\text { absorptive capcacity }\end{array}$ & $\begin{array}{l}\text { Part mix breadth } \\
\text { at the line }\end{array}$ & No influence \\
\hline $\mathrm{H} 2 \mathrm{~B}$ & $\begin{array}{l}\text { Assembly } \\
\text { line performance }\end{array}$ & $\begin{array}{l}\text { Assembly line } \\
\text { labor productivity }\end{array}$ & $\begin{array}{l}\text { Indirect task change } \\
\text { for which line has } \\
\text { absorptive capacity }\end{array}$ & $\begin{array}{l}\text { Part mix breadth at a } \\
\text { downstream assembly line }\end{array}$ & No influence \\
\hline
\end{tabular}


given narrow superset of parts. Thus, the focused set of parts that a production line started with did not change. This is a type of temporal change in requirements for which machining lines possessed the absorptive capacity as a function of their requirements in the prior period, and should adapt to easily. Next, in the assembly shop, the focus of the lines was on producing a high variety of products. Over time, while product-variety increased, this high product variety was not a new task for the assembly lines. Accordingly, we expect that the performance of the assembly lines does not change with a change in the part mix. Further, given the initial task of meeting the requirement of high end-product variety, assembly lines can adapt well to the proliferation of the end product, which is their downstream product. Formally, we propose the following hypotheses for each line.

H2A: Greater part-mix breadth processed by a machining line or assembly line has no influence on the line's performance.

H2B: Greater part-mix breadth processed by an assembly line has no influence on the performance of a corresponding upstream assembly line.

Table 4 summarizes the conceptual and operational dependent and independent variables for the propositions and hypotheses. Because of the formulation of the hypotheses, the rejection criterion for hypotheses H1A and H1B is the lack of statistically significant support. Conversely, the rejection criterion for hypothesis $\mathrm{H} 2 \mathrm{~A}$ and $\mathrm{H} 2 \mathrm{~B}$ is the presence of sufficient statistically significant contradictory evidence.

In conclusion, this section presents two sets of hypotheses. The predictions correspond to the two propositions and suggest that the performance of focused production lines will decline only when the lines adopt new manufacturing requirements that are outside the scope of the absorptive capacity developed through the execution of their prior manufacturing requirements. The hypotheses address direct changes occurring at the machining lines and the assembly lines, as well as indirect changes occurring at interrelated downstream production lines. For hypothesis testing, the generalizable variables are specific to the case in their operationalization. In the next section, we describe the empirical methods and results.

\section{Empirical methods and results}

This section first describes the models we used to test the hypotheses. We then discuss the statistical estimation procedures and the data used for testing. Finally, we present the empirical results and discuss their implications.

\subsection{Model and estimation procedure}

Empirically testing the hypotheses involves examining relationships across several production lines between the variables over time. We expect that the relationships will vary across the production lines, but not over time at a given line. The conditions of time-invariance and unit-variance make the test equivalent to postulating a separate regression for each unit (Hsaio, 1985, pp. 128-153). Accordingly, at each line, we first propose the following general model for production line performance.

$$
\begin{aligned}
\text { Performance }_{t}= & \mathrm{B} 0+\mathrm{B} 1 \log T+\mathrm{B} 2 \mathrm{Mix}_{t}+\mathrm{B} 3 \mathrm{Het}_{t} \\
+ & \mathrm{B} 4 \mathrm{NextMix}{ }_{t+1}+e_{t} \text { (for the } \\
& t-\text { th observation of time })
\end{aligned}
$$

where $e_{t}$ is the residual term of the regression, $\mathrm{B} 0$ is the intercept, and B1, B2, B3, and B4 are multiple time-series regression coefficients. The independent variables have the following definitions.

$\log T$ : The base-10 logarithm of time $(T)$. We expect that, in addition to the focus variables of our interest, the learning that takes place at a line over time will influence absorptive capacity and performance. Consistent with the logarithmic nature of the learning curve, we represent the time variable in logarithmic form.

$\operatorname{Mix}_{t}$ : The part mix processed at a line at time $t$, as we discussed in Section 5.

$\mathrm{Het}_{t}$ : The heterogeneity of volumes of products processed at a line at time $t$, as we discussed in Section 5 .

NextMix $_{t+1}$ : The part mix processed at the downstream line at time $t+1$. We use a lead-time variable to represent the production lead-times within the facility.

Finally, we note that to the extent that absorptive capacity is also a function of the recipient, that is, the production line, it can have two components, 
Table 5

\begin{tabular}{|c|c|c|c|c|}
\hline \multicolumn{5}{|c|}{ A. Variable operationalization } \\
\hline Variable & Description & Construct & Data source & Discussion \\
\hline $\begin{array}{l}\text { Part Mix } \\
\text { Breadth }\left(\operatorname{Mix}_{t}\right)\end{array}$ & $\begin{array}{l}\text { Part Mix } \\
\text { at time } t\end{array}$ & $\begin{array}{l}\text { Number of } \\
\text { bills of material }\end{array}$ & $\begin{array}{l}\text { 1986-1990: } \\
\text { Monthly production } \\
\text { volumes for each } \\
\text { of } 1300 \text { part numbers }\end{array}$ & $\begin{array}{l}\text { Each component, } \\
\text { sub-assembly, } \\
\text { or assembly has } \\
\text { its own unique part- } \\
\text { number. The appropriate } \\
\text { measure of part-mix at } \\
\text { a line in a given month } \\
\text { is the number of part } \\
\text { numbers the line processed. }\end{array}$ \\
\hline $\begin{array}{l}\text { Part Volume } \\
\text { Heterogeneity }\left(\mathrm{Het}_{t}\right)\end{array}$ & $\begin{array}{l}\text { Part Volume } \\
\text { Heterogeneity at time } t\end{array}$ & $\begin{array}{l}\text { Hirschman Index of } \\
\text { part volumes (HINDEX) }\end{array}$ & Same as above & $\begin{array}{l}\text { We use the Hirschman Index } \\
\text { to measure the dispersion } \\
\text { between the aggregate } \\
\text { monthly volumes of part } \\
\text { numbers at a line (HINDEX). } \\
\text { For } n \text { variables } x_{1}, \ldots, x_{n} \text {, } \\
\text { HINDEX }=\sum x_{i}^{2} /\left(\sum x_{i}\right)^{2} \text {, } \\
\text { for all } i=1, \ldots, n \text {. For a given } \\
\text { number of parts, a higher } \\
\text { HINDEX indicates a greater } \\
\text { heterogeneity of volume, } \\
\text { and a greater deviation from } \\
\text { the focus on high volumes. }\end{array}$ \\
\hline $\begin{array}{l}\text { Downstream } \\
\text { Part Mix Breadth } \\
\left(\text { NextMix }_{t+1}\right)\end{array}$ & $\begin{array}{l}\text { Downstream } \\
\text { Part Mix at time } t+1\end{array}$ & $\begin{array}{l}\text { Number of bills } \\
\text { of material }\end{array}$ & Same as above & $\begin{array}{l}\text { Measured at } \\
\text { two levels through the } \\
\text { number of bills of } \\
\text { material of compressors. } \\
\text { The first is the end-product, } \\
\text { the 17-digit CR, that we describe } \\
\text { in Section 4.2.2. In addition, } \\
\text { we measure proliferation for } \\
\text { the 'core compressor,' that is, } \\
\text { compressor without peripherals }\end{array}$ \\
\hline
\end{tabular}

Part Mix Breadth

$\left(\right.$ NextMix $\left._{t+1}\right)$ $\begin{array}{ll}\text { Downstream } & \begin{array}{l}\text { Number of bills } \\ \text { of material }\end{array}\end{array}$

compressor without peripherals 


\section{Labor Productivity \\ (LaborProductivity $_{t}$ )}

Conformance

Quality

(Conformance $_{t}$ )
Labor Productivity

at time $t$

Direct labor

hours per unit

Conformance Quality

(Internal Failure

Cost)

Scrap treatment

hours per

unit output such as fittings, mountings,

and electrical components.

The core compressor is tracked as the '13-digit CR' within

the Copeland system. The core

compressor is the downstream

product for all machining

lines and three sub-assembly

lines, while the end-product is

the downstream product for one sub-

assembly line and all but one

assembly line. The exception is

the one assembly line that

packages the final product.

Measured through labor

6-1990:

Actual direct

labor hours by mont

by cost center, and

hours per unit produced.

Labor-hour data is available

by production line since

production line is a cost

center. Labor hour per

unit is the ratio of monthly

labor hours to monthly aggregate

volume for each production line.

Higher labor-hours per unit

indicate a lower productivity.

Scrap treatment labor

986-1988

Actual hours

hours per unit of goo

product provide an indirect

measure (data on actual

quality performance are

limited). ${ }^{\mathrm{b}}$ This is

consistent with Juran's

discussion of internal

failure as a component

of the cost of quality

(Juran, 1979). A higher

defective rate results

in higher scrap treatment

hours per unit of good product. 


\begin{tabular}{|c|c|c|c|c|c|c|c|}
\hline \multicolumn{8}{|c|}{ B. Descriptive statistics } \\
\hline Production line & Focus variable & Variable measure & $N$ & Minimum & Maximum & Mean & Standard deviation \\
\hline \multirow[t]{2}{*}{$\overline{\text { ML1 }}$} & Part mix & \# of BOMs & 48 & 2 & 3 & 2.96 & 0.199 \\
\hline & Volume Heterogeneity & Hirschman Index & 48 & 0.37 & 0.72 & 0.490 & 0.089 \\
\hline \multirow[t]{2}{*}{ ML2 } & Part mix & \# of BOMs & 48 & 1 & 6 & 2.61 & 1.204 \\
\hline & Volume Heterogeneity & Hirschman Index & 48 & 0.30 & 1.0 & 0.699 & 0.266 \\
\hline \multirow[t]{2}{*}{ ML3A } & Part mix & \# of BOMs & 48 & 5 & 13 & 9.05 & 1.779 \\
\hline & Volume Heterogeneity & Hirschman Index & 48 & 0.12 & 0.35 & 0.189 & 0.048 \\
\hline \multirow[t]{2}{*}{ ML3B } & Part mix & \# of BOMs & 48 & 1 & 7 & 4.22 & 1.373 \\
\hline & Volume Heterogeneity & Hirschman Index & 48 & 0.19 & 1.0 & 0.393 & 0.193 \\
\hline \multirow[t]{2}{*}{ ML4 } & Part mix & \# of BOMs & 48 & 1 & 3 & 2.02 & 0.322 \\
\hline & Volume Heterogeneity & Hirschman Index & 48 & 0.58 & 1.0 & 0.731 & 0.107 \\
\hline \multirow[t]{2}{*}{ ML5 } & Part mix & \# of BOMs & 48 & 3 & 9 & 4.878 & 1.252 \\
\hline & Volume Heterogeneity & Hirschman Index & 48 & 0.20 & 0.66 & 0.406 & 0.114 \\
\hline \multirow[t]{2}{*}{ ML6 } & Part mix & \# of BOMs & 48 & 8 & 20 & 13.98 & 2.634 \\
\hline & Volume Heterogeneity & Hirschman Index & 48 & 0.07 & 0.22 & 0.118 & 0.034 \\
\hline \multirow[t]{2}{*}{ ML7 } & Part mix & \# of BOMs & 48 & 2 & 5 & 3.265 & 0.758 \\
\hline & Volume Heterogeneity & Hirschman Index & 48 & 0.35 & 0.95 & 0.567 & 0.152 \\
\hline \multirow{2}{*}{ AL1 } & Part mix & \# of BOMs & 48 & 5 & 7 & 5.49 & 0.545 \\
\hline & Volume Heterogeneity & Hirschman Index & 48 & 0.17 & 0.33 & 0.227 & 0.032 \\
\hline \multirow[t]{2}{*}{ AL2 } & Part mix & \# of BOMs & 48 & 17 & 23 & 21.408 & 1.383 \\
\hline & Volume Heterogeneity & Hirschman Index & 48 & 0.06 & 0.12 & 0.083 & 0.014 \\
\hline \multirow[t]{2}{*}{ AL3 } & Part mix & \# of BOMs & 48 & 4 & 7 & 4.204 & 0.539 \\
\hline & Volume Heterogeneity & Hirschman Index & 48 & 0.37 & 0.72 & 0.480 & 0.075 \\
\hline \multirow[t]{2}{*}{ AL4 } & Part mix & \# of BOMs & 48 & 33 & 60 & 42.826 & 5.844 \\
\hline & Volume Heterogeneity & Hirschman Index & 48 & 0.05 & 0.07 & 0.059 & 0.0052 \\
\hline \multirow[t]{2}{*}{ AL5 } & Part mix & \# of BOMs & 48 & 32 & 52 & 41.653 & 3.892 \\
\hline & Volume Heterogeneity & Hirschman Index & 48 & 0.04 & 0.12 & 0.071 & 0.015 \\
\hline \multirow[t]{2}{*}{ AL6 } & Part mix & \# of BOMs & 48 & 32 & 52 & 41.653 & 3.892 \\
\hline & Volume Heterogeneity & Hirschman Index & 48 & 0.04 & 0.12 & 0.071 & 0.015 \\
\hline \multirow[t]{2}{*}{ AL7 } & Part mix & \# of BOMs & 48 & 32 & 52 & 41.653 & 3.892 \\
\hline & Volume Heterogeneity & Hirschman Index & 48 & 0.04 & 0.12 & 0.071 & 0.015 \\
\hline \multirow[t]{2}{*}{ AL8 } & Part mix & \# of BOMs & 48 & 62 & 148 & 97.796 & 22.443 \\
\hline & Volume Heterogeneity & Hirschman Index & 48 & 0.02 & 0.05 & 0.038 & 0.007 \\
\hline
\end{tabular}

${ }^{a}$ We find volume heterogeneity being measured only indirectly using perceptual Likert-Type scales in the Operations Management literature. Our search for a direct measurement leads us to other literature where we find the Hirschman Index to be a popular measure of this construct (Scherer and Ross, 1990). The symbolic expression is adapted from Tirole (1989), pp. 221-222.

${ }^{\mathrm{b}}$ The data for the quality measure are available for a 17 -month period, reducing the number of independent variables and the statistical strength of our results. Further, the concerned cost center collects these data for the factory as a whole rather than for each line. Also, for three assembly lines, AL5, AL6, and AL7, we can estimate only one equation because data is available for the same part mix and volume heterogeneity that they process in sequence, resulting in one rather than three separate relationships with conformance quality. 
static and dynamic. The static recipient component represents time-invariant properties of a production line that affect the line's ability to adapt to a change in requirement. The intercept term B0 will capture the static component. The B1 term captures the dynamic recipient, as we explained above in connection with the $\log T$ variable. We expect that including these aspects of absorptive capacity in the model will generate better estimates of the effects we are interested in.

We estimate the two equations separately for each production line. We then use the consistency of patterns of a regression coefficient across production lines as the basis for inferences about hypotheses.

We undertake the following three steps for each equation. First, we estimate Eq. (1) using time-series production data for machining line ML1. We estimate the full model rather than making any automatic selection. Since we are testing with time-series data, we test for auto-correlation during each estimate using the Durbin-Watson $d$-statistic and residual plots. Where auto-correlation is present, we use time-series transformation of the data using first differences, re-estimate the equation, and again test for auto-correlation as above. Consistent with many time-series analyses, first differencing removes auto-correlation in our testing. Second, we repeat the above procedure 16 times to estimate Eq. (1) separately for all 16 production lines.

Third, we examine the cross-sectional consistency of sign and significance of each regression coefficient to draw inferences. This approach to testing with longitudinal data borrows strengths across units of analysis and, consequently, can make inferences more robust than those from single time series data (Diggle et al., 1994, pp. 2-22). The magnitude of the coefficients at the site can vary widely across production lines since different lines make different products using different nominal unit labor hours. Therefore, we use the standardized rather than nonstandardized regression coefficients for better comparability across production lines.

\subsection{Data and measurement of variables}

This case study is consistent with several others (Mintzberg and McHugh, 1985; Sutton and Callahan, 1987; Eisenhardt and Bourgeois, 1988) in its seeking both quantitative and qualitative evidence. We retrieved the quantitative data from company records. Table 5A and $\mathrm{B}$ summarize the measurement and data sources of the variables that we used to test hypothesis sets $\mathrm{H} 1$ and $\mathrm{H} 2$.

We first address the production line focus variables. Consistent with our discussion of the variables in Section 5, we measure the part-mix at a production line through the number of parts. We capture volume heterogeneity through the dispersion between the several aggregate monthly volumes of the several part numbers at a line using the Hirschman Index (HINDEX) as a measure. Testing hypotheses $\mathrm{H} 1 \mathrm{~B}$ and $\mathrm{H} 2 \mathrm{~B}$ requires measuring focus variables at two levels. Table 5A contains the details of measurements and data sources.

We operationalize production line performance in terms of labor productivity and conformance quality. The traditional measurement of labor productivity reflects the efficiency of the transformation process occurring at a production line. Changes in the execution of the transformation process may result in new or modified routines that are outside the repertoire of routines that a production line can execute without conscious overview. Change can, therefore, slow the pace of execution of routines at a production line. Further, change can also lead to a mismatch between the task information needs and the information processing abilities of the line. A production line may absorb the additional task information needs by under-utilizing its resources, including labor resources (Galbraith, 1977). Therefore, labor productivity reflects the efficiency with which members of a line execute their routines. This is also consistent with the use in the literature of non-deterioration in performance in the face of change as a measure of adaptability (Upton, 1995). We measure labor productivity using the units produced per direct labor hour.

Note that the dependent variable of our interest is the productivity of direct labor only. While we expect that increasing part mix or volume heterogeneity will have a detrimental effect on indirect labor performance as well, one can easily explain this an effect by factors such as increased set-ups and material handling. Such a finding would be obvious rather than interesting. Consequently, we estimated Eq. (1) with indirect labor productivity as a dependent vari- 
able as sensitivity analysis, obtaining the expected results, but we do not report the results here.

Our second measure of production line performance is conformance quality. When a change in task stretches the production routines, the executed routines may not conform to the designed ones. The effect of non-conforming routines of the transformation process may be a less than desired quality of the process itself. A production line may also absorb a mismatch between task information needs and information processing capabilities by not meeting the additional task need fully, and thereby, by not conforming to the design of the task. An indicator of the quality of the process is the conformance quality of the parts produced by the process. We use a surrogate measure of conformance quality, measuring the cost of rework and rejects within the facility.

We estimate full model (1) when productivity is the dependent variable. However, the data limitations we noted in Table 5A lead us to estimate a simplified model of the following form when conformance quality is the dependent variable.

$$
\begin{aligned}
& \text { Conformance }_{t} \\
& =\mathrm{B} 5+\mathrm{B} 6 \mathrm{Mix}_{t}+{\mathrm{B} 7 \mathrm{Het}_{t}+e_{t}, \ldots} \times(\text { for the } t-\text { th observation of time })
\end{aligned}
$$

The Mix ${ }_{t}$ and Het ${ }_{t}$ terms in Eq. (2) are equivalent to those that we explained for Eq. (1). Among the coefficients, B5 is the intercept, while B6 and B7 are regression coefficients. A comparison of Eq. (1) with Eq. (2) indicates that we can test hypotheses $1 \mathrm{~A}$ and $1 \mathrm{~B}$ with both the dependent variables, but hypotheses $2 \mathrm{~A}$ and $2 \mathrm{~B}$ with productivity variables only.

Table 5B presents the descriptive statistics. All of the variables exhibit variation, while the degree of variation changing from line to line. To reflect the operational realities of the site, we use two simple data transformations. First, given that our data is on a monthly basis, we account for production lead-times of about two to three weeks by assuming that of the products that a line finished in a given month, production of half of them started in the previous month and the production of the other half started in the current month. Second, to mitigate the effects of end-of-the-month pushes to meet production targets, we use a moving average of labor productivity.

We estimate 16 time-series equations for labor productivity and 14 equations for conformance quality. Separately for the two dependent variables, we then seek robustness by comparing regression coefficients for each independent variable across production lines. Subsequently, we conducted unstructured interviews with managers, supervisors, and manufacturing support staff in order to verify our model and to learn more about the implications of the empirical results. In the next section, we present and discuss the results of testing the hypotheses in the order proposed.

\subsection{Hypotheses testing: results and discussion}

Table 6 summarizes the results of estimating a total of 30 time-series equations. The results provide reasonable support for $\mathrm{H} 1 \mathrm{~A}$ and $\mathrm{H} 1 \mathrm{~B}$, with mixed support for $\mathrm{H} 2 \mathrm{~A}$ and $\mathrm{H} 2 \mathrm{~B}$.

\subsubsection{Results}

Two tables report the detailed results of estimating Eqs. (1) and (2). Table 7A presents results of the labor productivity analysis. We summarize the results of Table 7A in B. For each estimation of Eq. (1), Table 7A shows the regression coefficients and

\begin{tabular}{|c|c|c|c|c|}
\hline $\begin{array}{l}\text { Type of } \\
\text { production line }\end{array}$ & $\begin{array}{l}\text { Focus variable } \\
\text { Performance variable }\end{array}$ & $\begin{array}{l}\text { Part volume Heterogeneity } \\
\left(\text { Het }_{t}\right) \text { H1A (expected results) }\end{array}$ & $\begin{array}{l}\text { Part mix breadth }\left(\mathrm{Mix}_{t}\right) \\
\text { H2A (mixed results) }\end{array}$ & $\begin{array}{l}\text { Downstream part mix breadth } \\
\left(\text { NextMix }_{t+1}\right) \text { H1B, H2B }\end{array}$ \\
\hline \multirow[t]{2}{*}{ Machine } & Labor productivity & Detrimental impact & No impact (expected) & $\begin{array}{l}\text { Detrimental Impact } \\
\text { (H1B, expected })\end{array}$ \\
\hline & Conformance quality & Detrimental impact & Detrimental impact (unexpected) & Not tested \\
\hline \multirow[t]{2}{*}{ Assembly } & Labor productivity & Detrimental impact & No impact (expected) & $\begin{array}{l}\text { Mixed Impact } \\
(H 2 B, \text { mixed })\end{array}$ \\
\hline & Conformance quality & Detrimental impact & Detrimental impact (unexpected) & Not tested \\
\hline
\end{tabular}

Table 6

Impact of defocusing on production line performance: summary results 
Table 7

A. Regression estimates of impact of focus change on labor productivity (positive coefficients indicate higher labor hours)

\begin{tabular}{|c|c|c|c|c|c|c|c|c|c|}
\hline \multirow[t]{2}{*}{ Labor hours per unit } & \multicolumn{4}{|l|}{$\begin{array}{l}\text { Regression coefficients, } \\
\text { standardized } \\
\text { ( } t \text {-values, level of confi- } \\
\text { dence) }\end{array}$} & \multicolumn{3}{|c|}{ Model summary } & \multicolumn{2}{|c|}{ Analysis of variance } \\
\hline & $\log T$ & $\operatorname{Mix}_{t}$ & Het $_{t}$ & NextMix $_{t+1}$ & $\begin{array}{l}\text { Durbin- } \\
\text { Watson } d^{\text {a }}\end{array}$ & $R$-square & $\begin{array}{l}\text { Adjusted } \\
R \text {-square }\end{array}$ & $\begin{array}{l}\text { Residual } \\
F \text {-ratio }\end{array}$ & $\begin{array}{l}\text { Signifi- } \\
\text { cance }\end{array}$ \\
\hline \multicolumn{10}{|l|}{ Machine } \\
\hline ML1 & $-0.040(0.249, \mathrm{n} / \mathrm{s})$ & $0.187(1.10, \mathrm{n} / \mathrm{s})$ & $0.257(1.918,0.95)$ & $0.516(3.577,0.99)$ & 2.261 & 0.349 & 0.284 & 5.369 & 0.001 \\
\hline ML2 & $0.122(0.921, \mathrm{n} / \mathrm{s})$ & $-0.136(0.960, \mathrm{n} / \mathrm{s})$ & $0.278(1.93,0.95)$ & $0.486(3.729,0.99)$ & 1.897 & 0.328 & 0.260 & 4.874 & 0.003 \\
\hline ML3a & $0.076(0.540, \mathrm{n} / \mathrm{s})$ & $0.144(0.995, \mathrm{n} / \mathrm{s})$ & $0.212(1.452,0.90)$ & $0.370(2.605,0.99)$ & 1.981 & 0.218 & 0.140 & 2.796 & 0.039 \\
\hline ML3b & $0.086(0.627, \mathrm{n} / \mathrm{s})$ & $-0.100(0.697, \mathrm{n} / \mathrm{s})$ & $0.246(1.706,0.95$ & $0.382(2.788,0.99)$ & 2.019 & 0.257 & 0.183 & 3.461 & 0.016 \\
\hline ML4 & $0.153(1.147, \mathrm{n} / \mathrm{s})$ & $-0.006(0.043, \mathrm{n} / \mathrm{s})$ & $0.016(0.104, \mathrm{n} / \mathrm{s})$ & $0.524(3.863,0.99)$ & 2.141 & 0.294 & 0.224 & 4.172 & 0.006 \\
\hline ML5 & $-0.052(0.347, \mathrm{n} / \mathrm{s})$ & $-0.163(0.986, \mathrm{n} / \mathrm{s})$ & $0.085(0.543, \mathrm{n} / \mathrm{s})$ & $0.299(1.840,0.95)$ & 1.973 & 0.382 & 0.146 & 1.619 & 0.189 \\
\hline ML6 & $0.040(0.295, \mathrm{n} / \mathrm{s})$ & $-0.275(1.979,0.95)$ & $0.239(1.727,0.95)$ & $0.377(2.798,0.99)$ & 2.366 & 0.280 & 0.208 & 3.894 & 0.009 \\
\hline ML7 & $0.294(2.09,0.95)$ & $0.382(2.682,0.99)$ & $0.363(2.482,0.99)$ & $0.260(1.904,0.95)$ & 2.063 & 0.328 & 0.262 & 4.998 & 0.002 \\
\hline \multicolumn{10}{|l|}{ Assembly } \\
\hline AL1 & $0.162(1.069, \mathrm{n} / \mathrm{s})$ & $0.203(1.252, \mathrm{n} / \mathrm{s})$ & $-0.016(0.100, \mathrm{n} / \mathrm{s})$ & $0.488(3.383,0.99)$ & 2.203 & 0.285 & 0.216 & 4.178 & 0.006 \\
\hline AL2 & $0.206(1.43,0.90)$ & $-0.134(0.883, \mathrm{n} / \mathrm{s})$ & $-0.136(0.940, \mathrm{n} / \mathrm{s})$ & $-0.310(2.051,0.95)$ & 2.159 & 0.186 & 0.105 & 2.285 & 0.077 \\
\hline AL3 & $0.253(1.86,0.95)$ & $0.069(0.499, \mathrm{n} / \mathrm{s})$ & $0.347(2.476,0.99)$ & $-0.359(2.627,0.99)$ & 2.036 & 0.263 & 0.189 & 3.567 & 0.014 \\
\hline AL4 & $-0.024(0.136, \mathrm{n} / \mathrm{s})$ & $0.102(0.347, \mathrm{n} / \mathrm{s})$ & $0.409(2.34,0.95)$ & $0.670(2.101,0.95)$ & 2.082 & 0.328 & 0.265 & 5.136 & 0.002 \\
\hline AL5 & $-0.153(0.796, \mathrm{n} / \mathrm{s})$ & $-0.087(0.481, \mathrm{n} / \mathrm{s})$ & $0.556(2.607,0.99)$ & $0.802(3.621,0.99)$ & 2.350 & 0.304 & 0.237 & 4.577 & 0.004 \\
\hline AL6 & $0.099(0.463, \mathrm{n} / \mathrm{s})$ & $0.272(1.197, \mathrm{n} / \mathrm{s})$ & $0.485(2.194, .095)$ & $0.327(1.119, \mathrm{n} / \mathrm{s})$ & 1.977 & 0.217 & 0.144 & 2.973 & 0.030 \\
\hline AL7 & $0.022(0.111, \mathrm{n} / \mathrm{s})$ & $0.285(1.343,0.90)$ & $0.432(2.095,0.95)$ & $0.483(1.770,0.95)$ & 2.086 & 0.318 & 0.255 & 5.023 & 0.002 \\
\hline AL8 & $-0.164(0.871, \mathrm{n} / \mathrm{s})$ & $0.862(4.130,0.99)$ & $0.548(2.36,0.95)$ & not applicable & 2.383 & 0.280 & 0.231 & 5.697 & 0.002 \\
\hline
\end{tabular}

B. Signs and significance of the coefficients of (A.) (Labor Productivity) (positive coefficients indicate higher labor hours)

\begin{tabular}{|c|c|c|c|c|c|c|c|}
\hline & & \multirow[t]{2}{*}{ Expected } & \multicolumn{5}{|c|}{ Number of coefficients } \\
\hline & & & $\begin{array}{l}\text { Positive and } \\
\text { significant at } 90 \% \\
\text { level }(95 \%, 99 \%)\end{array}$ & $\begin{array}{l}\text { Negative and } \\
\text { significant at } 90 \% \\
\text { level }(95 \%, 99 \%)\end{array}$ & $\begin{array}{l}\text { Not } \\
\text { significant } \\
\text { at } 90 \%\end{array}$ & Total & Inference \\
\hline 1 & Machining lines Direct Labor & & & & & & \\
\hline $1 \mathrm{a}$ & HINDEX of Part Volumes ( Het $_{t}$ ) & + & $6(5,1)$ & $0(0,0)$ & 2 & 8 & Consistent with H1A \\
\hline $1 \mathrm{~b}$ & Number of Part Numbers $\left(\right.$ Mix $\left._{t}\right)$ & 0 & $1(1,1)$ & $1(1,0)$ & 6 & 8 & Consistent with $\mathrm{H} 2 \mathrm{~A}$ \\
\hline $1 \mathrm{c}$ & Next BOM $\left(\right.$ NextMix $\left._{t+1}\right)$ & + & $8(6,6)$ & $0(0,0)$ & 0 & 8 & Consistent with H1B \\
\hline 2 & Assembly lines direct labor & & & & & & \\
\hline $2 a$ & HINDEX of part volumes $\left(\mathrm{Het}_{t}\right)$ & + & $6(6,2)$ & $0(0,0)$ & 2 & 8 & Consistent with H1A \\
\hline $2 \mathrm{~b}$ & Number of part numbers $\left(\mathrm{Mix}_{t}\right)$ & 0 & $2(1,1)$ & $0(0,0)$ & 6 & 8 & Consistent with $\mathrm{H} 2 \mathrm{~A}$ \\
\hline $2 \mathrm{c}$ & Next BOM $\left(\right.$ NextMix $\left._{t+1}\right)$ & 0 & $4(4,2)$ & $2(2,1)$ & 2 & 8 & Inconsistent with $\mathrm{H} 2 \mathrm{~B}$ \\
\hline
\end{tabular}

Number of observations $=45$

$\mathrm{n} / \mathrm{s}$ : not significant.

${ }^{\mathrm{a}}$ Acceptable range of $d$-statistic for this data set is between 1.63 and 2.37 (Durbin and Watson, 1951). 
their significance, an overall model summary including the Durbin-Watson $d$-statistic and $R$-squared and adjusted $R$-squared values, and an analysis of variance. The $R$-squared values suggest that the equations measure a material amount of variance, without fully explaining the outcomes. $R$-squares in this range of about 0.1 to 0.3 are common in regression analyses of outcomes that arise from many causes. For each independent variable, Table 7B lists the number of coefficients in Table 7A with positive and negative signs at different levels of significance grouped into the two shops, machining and assembly. Table $8 \mathrm{~A}$ and $\mathrm{B}$ repeat for conformance quality what Table 7A and B depict for labor productivity.

The results of the study are consistent with hypothesis H1A in machining, that performance of each production line declines as the heterogeneity of volumes of parts processed at the line increases. First, we test the hypothesis at the machining shop with labor productivity as the performance measure. Row 1a of Table 7B shows that six out of the eight coefficients are positive and significant at the $90 \%$ level or above. Further, there is no negative coefficient. Thus, there is strong evidence consistent with the hypothesis of detrimental impact. Next, the study is consistent with hypothesis $\mathrm{H} 1 \mathrm{~A}$ in the machining shop when conformance quality is the measure of performance as well. With respect to conformance quality results, we note from Table $5 \mathrm{~A}$ that we cannot expect the same level of statistical confidence as we had with labor productivity results, owing to the smaller number of cases. Row 1a of Table $8 \mathrm{~B}$ shows that five out the eight coefficients are positive and significant at $90 \%$ level or above, while two more also are positive, although at slightly lower levels at significance. Only one coefficient is negative. Therefore, with one exception, the results suggest that volume heterogeneity generally leads to reduced conformance quality at machining lines.

The results of the study are consistent with H1A in assembly as well. With labor productivity as the performance measure, row $2 \mathrm{a}$ of Table $7 \mathrm{~B}$ shows that six out of the eight coefficients are positive and significant at the $95 \%$ level or above. The other two are insignificant. Thus, there is strong support for the hypothesis of detrimental impact. Within the statistical limits noted above for conformance quality, the study is consistent with hypothesis H1A in assembly with conformance quality at performance measure as well. Row $2 \mathrm{a}$ of Table $8 \mathrm{~B}$ shows that three coefficients are positive and significant at $90 \%$ level or above, while two of the other three coefficients are positive and significant at the $87.5 \%$ level. There is no negative coefficient. Therefore, within the statistical limitations noted above, the results suggest that volume heterogeneity at assembly lines tends to reduce conformance quality.

The results of the study are consistent with hypothesis H1B, that labor productivity of each machining line declines as the part mix at its corresponding downstream assembly line broadens. Row 1c of Table 7B shows that of all eight of the eight coefficients are positive and significant at the $90 \%$ level or above. Thus, the hypothesis receives strong support.

The results for $\mathrm{H} 2 \mathrm{~A}$, that greater part mix breadth processed by a machining line or assembly line has no influence on the line's performance, are mixed, and depend on the pair of variables used for testing. The study is consistent with hypothesis $\mathrm{H} 2 \mathrm{~A}$ at machining lines and assembly lines when productivity is the measure of performance. Row $1 \mathrm{~b}$ of Table $7 \mathrm{~B}$ shows that six out of the eight machining line coefficients are insignificant, and one is significant and negative, supporting the hypothesis. Row $2 \mathrm{~b}$ of Table 7B, meanwhile, shows that of the eight assembly line coefficients, six are insignificant and only two are positive at $90 \%$ level. Therefore, the results suggest that in general, increased part-mix breadth does not detrimentally affect labor productivity of an assembly line or machining line, as expected. The study is not consistent with hypothesis $\mathrm{H} 2 \mathrm{~A}$ at machining lines or assembly lines when conformance quality is the measure of performance, since the evidence is mixed. Row $1 \mathrm{~b}$ of Table $8 \mathrm{~B}$ shows that four of seven machining line coefficients are positive and significant at the $90 \%$ level or above. Similarly, Row $2 b$ shows that that four of six assembly line coefficients are positive and significant at the $90 \%$ level or above. Therefore, there is adequate contradictory evidence to reject the hypothesis of no detrimental impact.

The results of the study are not consistent with hypothesis $\mathrm{H} 2 \mathrm{~B}$, that labor productivity of each assembly line is not detrimentally affected as the part mix at its corresponding downstream level broadens. 
Table 8

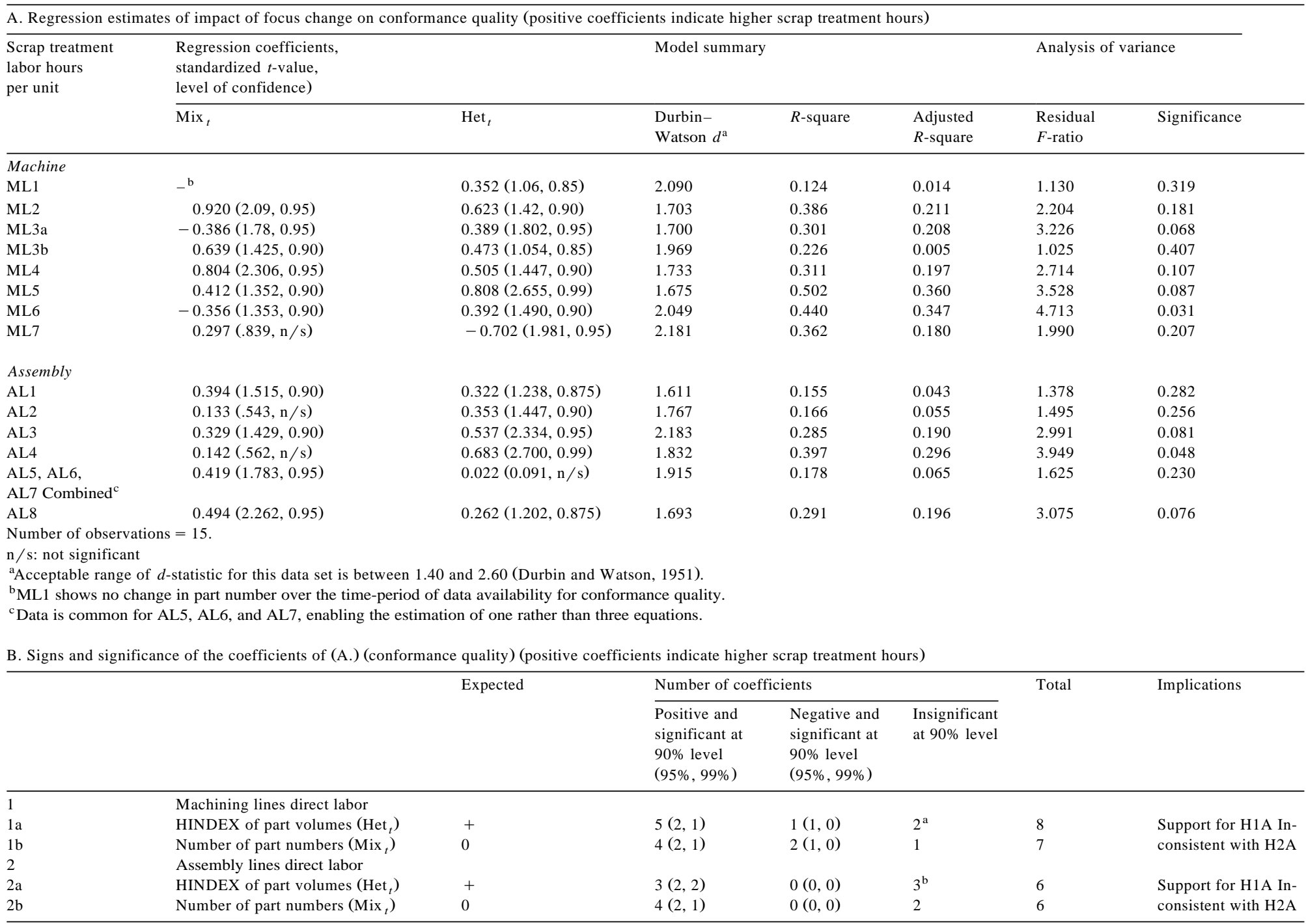

${ }^{a}$ Both are positive and significant at $85 \%$ level.

${ }^{\mathrm{b}}$ All three are positive, two significant at $87.5 \%$ level. 
Row 2c of Table 7B shows mixed evidence. While four coefficients are consistent with the prediction (two non-significant and two negative), four coefficients are positive and significant. Thus, there is adequate contradictory evidence to reject the hypothesis of no detrimental impact. We discuss in the next section how our subsequent examination explains some of this unexpected relationship.

\subsubsection{Discussion of the labor productivity results}

One overall conclusion from the results is that in both shops, consistent with the hypotheses, change of part-mix does not affect labor productivity. It is interesting to note that there is almost an order of magnitude difference in part-mix breadth between most machining lines and most assembly lines (See Table 5B for descriptive statistics). The commonality between the two widely differing operating ranges is that they are, nonetheless, focused operating ranges for individual production lines. Interestingly, AL8, which is a very strong exception to the general lack of impact of part mix on labor productivity, also has an exceptional profile of part mix. Line by line examination shows that, while the part mix at the other assembly lines is wide, the part mix at AL8 is continuously widening. It seems, therefore, that variation in part mix breadth does not affect labor productivity as long as the variation is within a limited range, narrow or wide. The exception of AL8 seems to support this general rule since part mix moves away from a stable, focused set.

In contrast to part mix breadth, volume heterogeneity detrimentally affects the labor productivity of production lines in both shops, as expected. It is obvious that partial substitution of large batches by small batches decreases the productivity of the indirect labor. More interesting is the result that volume heterogeneity negatively affects the productivity of direct labor. That is, volume heterogeneity represents a kind of change that disrupts the learning that can take place in an environment of repetitive, homogeneous volume, be it all small or all large volumes. The argument is that volume homogeneity can help decrease the direct costs through the application of learning principles, and unintended volume heterogeneity seems to obstruct this path of learning by repetition. It is unlikely that volume heterogeneity affects the technological processing routines, which may be mostly independent of the volume in which parts are processed. Rather, it is likely that volume heterogeneity affects the routines that co-ordinate the execution of technological processing routines.

\subsubsection{Discussion of the conformance quality results}

As seen above from the results, increases in both part-mix breadth and volume heterogeneity lead to increasing quality problems in both types of shops. One interesting result is that for several production lines, while labor productivity does not fall with part-mix breadth, as expected, conformance quality unexpectedly does decline. A possible explanation for the difference in the productivity and quality results is that when a broader part-mix stretches the routines at the lines, performance decline of the stretched routines may occur in the quality of execution of the routines rather than the pace of completion. Here, quality of execution of a routine means the conformance of an executed routine to its specifications.

The field interviews suggest a possible reason why focus may have distorted the role of the related infrastructural function, Quality Control (QC). Interestingly, the factory, which earned a reputation for quality in its early days, did not closely examine the functional task of QC in a changing environment. The reason may lie in a managerial perception that, "The task of QC essentially remained the same over time." That is, the change was considered a nonevent from a quality control point of view. Such a perception may be a consequence of what management understood focus to be, both as an objective and as a lever to limit demand. First, if a focused objective of low cost through high volume dominates the design of the QC system, then high-volume based inspection may become the focus of QC activity, rather than process quality improvement. Second, if management sees focus mainly as limiting the number of machined parts, and if that number does not proliferate, they may perceive no need to change the functional task of QC. One may easily extend this argument to tasks of other manufacturing support functions.

\subsubsection{Joined systems results}

Support for hypothesis H1B suggests that the inter-subsystem effects are very strong in the ma- 


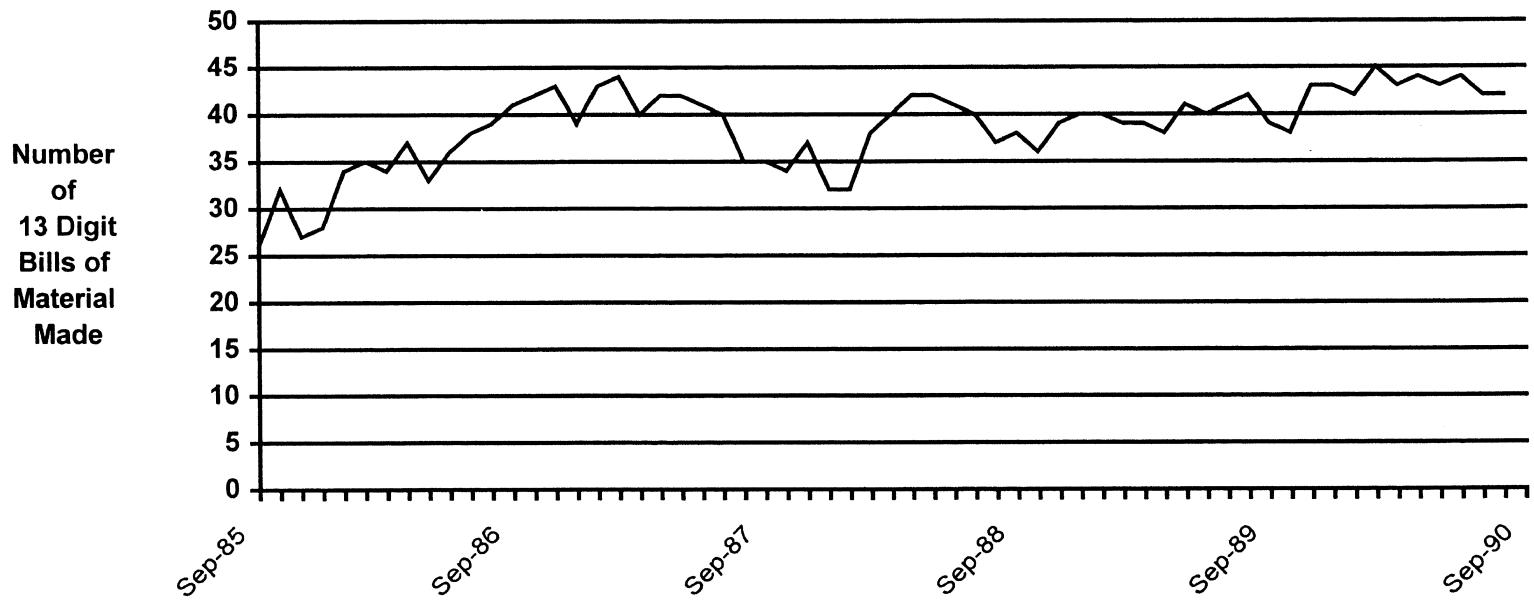

Time in month

Fig. 4. Product proliferation of 'Core' compressors, the 13-Digit CR: 1985-1990.

chining shop. One way to examine the functioning of the richly joined system of Ashby (1960) at the site is through the functioning of a system of the manufacturing infrastructure, namely, the production control system which 'joins' the production line subsystems. In a tightly coupled system, the demand pattern and inventory planning decisions downstream can greatly affect the demand pattern for parts at an upstream line. Indeed, the volume heterogeneity that impair labor productivity and conformance quality at machining lines, as tested earlier through hypotheses H1A, may be traced to this downstream proliferation. Hypothesis H1B makes this important connection explicit and thereby demonstrates the benefits of a more fine-grained understanding of focus.

A closer examination of the cross-sectional pattern of the results of hypothesis $\mathrm{H} 2 \mathrm{~B}$ suggests that assembly lines where the downstream product is the 17-digit CR show a detrimental effect of proliferation, whereas assembly lines where the downstream product is the 13-digit $\mathrm{CR}$ produces mixed evidence. ${ }^{3}$ A comparison of proliferation of the 17-digit CR (Fig. 3) vs. the 13-digit CR (Fig. 4) show distinct patterns of variation at the two levels.

\footnotetext{
${ }^{3}$ The '17-digit CR' and the '13-digit CR' are alphanumeric nomenclature systems for compressors with and without peripheral components, respectively, as noted in Section 4.2.2 and Table $5 \mathrm{~A}$.
}

The part mix at the 13-digit level has wide variation through the period, but very little trend. That is, part mix varies within a broad set that it started with, so that the factory did not lose its focus on this measure. In contrast, the 17-digit $\mathrm{CR}$, as we noted earlier in Section 4, shows a clear upward trend after a short initial stable period. That is, the factory compromised its focus on the 17-digit product. We argue, therefore, that it is not the part mix breadth per se, but change in part mix from a focused set that seems to be the key determinant of performance.

\section{Implications and conclusions}

Our results suggest that changes in manufacturing requirements may come from various sources, and that production lines may resist an unintended change even if the lines have the ability to respond favorably to an intended change. In terms of focus variables, we found that the labor productivity of lines in both shops generally responded favorably to change in part mix breadth, an intended change. In contrast, lines in both shops exhibit a detrimental impact of increasing volume heterogeneity, an unintended change, on labor productivity.

In terms of the relationships between focus variables and performance variables, the results show a detrimental effect of part mix change, which is a 
focal demand variable, on conformance quality, a non-focal performance variable. This stands in contrast to the general lack of detrimental impact of the same change on labor productivity, a focal performance variable. The detrimental impact of volume heterogeneity on conformance quality concerns a combination of an unintended change and a non-focal performance variable. This further underscores the point that of the many possible relationships between variables representing demand and those representing performance, many are between non-focal pairs of variables, and many include unintended changes.

We also find that inter-subsystem effects in the factory are very strong. That is, the performance of a production line may be affected by changes occurring elsewhere in an interconnected production system, as well as from changes occurring at the line itself. Such indirect effects mean that managerial attempts to achieve a low-cost target may fail, even if they retain the narrow part-mix in the machine shop, the ostensible focus of the factory in realizing its low-cost target. Costs at a machining line may increase if the part mix breadth expands at an assembly line that is connected to the machining line.

\subsection{Manufacturing management}

The implications for manufacturing management that we draw from this study address limits and paths to changing the manufacturing requirements of a factory. The key limiting factor we observe is that a deviation from focus may affect factory performance in unexpected ways. Issues arise in several areas, including implications for focal and complementary dimensions of manufacturing requirements and objectives, performance of connected systems, and differential influence of new and existing absorptive capacity.

Since absorptive capacity is cumulative, changes to operations occurring in controlling determinants, performance criteria, and processing stages other than the focal ones may go largely undetected. For example, managers may rely in their decisions about a change primarily on an analysis of the change along one focal controlling determinant. Such a decision-making approach makes the implicit yet restrictive assumption that the change does not impinge on any other determinant of focus that can affect performance. Consequently, there is a risk that management of change may occur through the monitoring of an inappropriate determinant of focus that may have no effect, or even an unintended effect on performance. This is analogous to attempting to control production costs without understanding the drivers of cost (Kaplan, 1984).

Focus may affect not only the determinants of demand on a factory, but also its performance objectives. We recognize that managers usually attempt to consider multiple performance objectives that relate to focal dimensions. However, managers may concentrate more on the objectives that are vital to succeeding in a market than those necessary to participate in the market. Hill (1989, pp. 36-46) refers to the two types of objectives as order winners and order qualifiers. This study indicates that due to the initial relative allocation of managerial attention and the cumulative nature of absorptive capacity, analysis of a proposed change may pay little attention to its effect on objectives other than the focal objective, which management views as the order-winner. Consequently, there is a risk that while the factory may be able to preserve its performance along the order winner dimension, poor performance along other dimensions may cause order disqualification. A dynamic environment compounds the risk, since order winner and order qualifier objectives may switch places or change drastically over time.

Our results also suggest that an analysis of a change needs to consider whether the task of a production unit can change as an indirect result of a change occurring at a connected unit. Connected units may include plants within a network, 'plantswithin-a-plant', and production lines within a plant which have specific benefits, such as greater system-wide capacity utilization (Graves and Jordan, 1991) and shared overhead resources (Skinner, 1974). Managers may have to explicitly understand and manage the trade-off between such benefits and the risk of indirect detrimental impact on performance. However, this understanding may be difficult because in the absence of any direct change, managers may mistakenly conclude that the task of their unit has not changed, while unknown indirect changes affect the unit. Consequently, production unit performance may suffer due to seemingly obscure reasons. 
Although some changes in manufacturing requirements cause performance problems, other changes provide paths for effective adaptation. In this study, the most effective changes required little or no new absorptive capacity relative to the traditional tasks of production lines. These changes may remain transparent to the production line routines. Transparent changes offer managers the opportunity to exploit and benefit from the change from perspectives such as marketing without harming manufacturing performance.

\subsection{General implications}

This study has implications for the streams of literature concerning focused factories, manufacturing flexibility, organizational change, and evolutionary change. The results also point to the need for careful consideration of units of analysis, while introducing conformance quality as a measure of performance.

The empirical contribution to the focused factory literature lies in establishing statistically supported relationships between determinants of focus and manufacturing performance criteria at the production line level. The decline in performance with respect to an unintended change, but not with respect to an intended change, including cases where the change occurs along the same variable, suggests that it may not be the absolute magnitude of a change variable, but the deviation from a focused operating range of that variable, that is an appropriate determinant of performance. This and the associated issue of metrics may explain in part why empirical studies of the effect of product variety on performance have produced mixed results (Hayes and Clark, 1985; Banker et al., 1990; Foster and Gupta, 1990; Kekre and Srinivasan, 1990; Anderson, 1995; Brush and Karnani, 1996; McDuffie et al., 1996). Further, the result that volume heterogeneity is a strong determinant of performance demonstrates the need for understanding changes in manufacturing requirement through dimensions other than the product dimension, which, as seen from the references cited above, is the most commonly researched dimension in the literature. This result may also explain in part the 'something real' that prevented Milgrom and Roberts (1990) from being able to include the number of products in a cluster of complements that maximize the profit function of a modern manufacturing firm.

The results also contribute to the literature on manufacturing flexibility by measuring and examining the concept of volume heterogeneity related to the type of flexibility labeled as 'volume flexibility,' which refers to the ability of a production system to operate economically at several levels of aggregate production volume (Browne et al., 1984; Sethi and Sethi, 1990; Gerwin, 1993). In a multi-product environment, volume heterogeneity can change without any change in the aggregate volume. We are unaware of other articles that systematically study it. Thus, there is a need to examine this aspect of flexibility separately with its own measure and enabling elements.

The results link manufacturing focus with research on organizational change by noting that manufacturing focus may be a condition under which development of absorptive capacity (Cohen and Levinthal, 1990) unrelated to current manufacturing task appears less attractive. Absorptive capacity is path dependent. Focus may define the boundaries of the path rather narrowly through emphasis on selected determinants, objectives and processing stages, and thereby trap production units to operate in the particular knowledge-domain of their initial focus. This raises an important question: what are the principles that may guide the appropriate balance between the benefits of specializing in the current task, and the future ability to adapt to tasks unrelated to the current one?

Our results apply the model of evolutionary change of Nelson and Winter (1982) in a production context, and suggest that we can examine the execution of routines from two aspects, pace and conformance. Both aspects may affect the performance of a production line trying to adapt new routines of a new task, affecting its productivity and quality, respectively. We may extend similar arguments about execution of routines to contexts other than production.

The strong inter-subsystem effects observed in explaining line performance highlight the importance of analyzing manufacturing change at low level units of analysis. The literature on complexity (Simon, 1960, 1979; Perrow, 1967, 1984; Weick, 1990) suggests that for complex systems, cause and effect relationships are unclear, and interactions and pro- 
cesses are poorly understood. In particular, Simon (1986) comments that consequently, rational inquiry requires extensive empirical research at the 'micromicro' level. This study comes closer to that level by using the production line as the unit of analysis. Given that most empirical research in Operations Management uses the factory as the unit of analysis (Swink and Speier, 1995), this research demonstrates the value of considering micro-level units for future research.

To our knowledge, this is also the first systematic empirical examination of conformance quality in focused factories. Our usage of an indirect measure of conformance quality, as well as weaker but expected relationships than with productivity, are both consistent with results obtained by McDuffie et al. (1996) in their examination of product variety. Both these studies speak to the need for further research that assesses both the relationship and the measurement issues concerning conformance quality.

Several limits apply to the study. It would be useful to examine the temporal pattern in changed performance following changes in manufacturing requirements, in order to determine which types of change lead to quick recovery and which lead to longer term reductions in performance. In addition, the study does not address several hierarchical levels and perspectives of focus within a manufacturing facility. Examination of advantages and disadvantages of focus at more hierarchical levels and from more perspectives is necessary for the development of an integrative theory of manufacturing focus. One major problem in such empirical examination is likely to be the measurement of focus. The list of determinants in Table 3 is less than complete at the factory level, and is only a beginning at the production line level. More serious problems, however, may lie in the measurement of the aspects of focus other than dimension, namely, manufacturing task, and tailoring of the system. Nonetheless, we believe that the results contribute to our understanding of how changes in manufacturing requirements affect the performance of a focused factory.

In conclusion, our results contribute to the literature in several ways. First, this work connects research on manufacturing focus with that of organizational change. Specifically, we utilize the organizational nature of production units including their rou- tines and absorptive capacity to analyze the limits and paths of changing the manufacturing requirements of production lines of a focused factory. Second, this work contributes to the research on manufacturing flexibility by rigorously examining the notion of volume heterogeneity as distinct from the concept of aggregate production volume flexibility. Finally, the study contributes to the empirical literature in Operations Management by demonstrating the value of using a micro-level unit of analysis, consistent with the literature on complexity, along multiple dimensions of manufacturing requirements as well as manufacturing performance.

The authors gratefully acknowledge the support that personnel of the Copeland have provided for this research. In addition, they express their thanks to the referees for their constructive comments.

\section{References}

Abernathy, W.J., 1978. The Productivity Dilemma. Johns Hopkins Univ. Press, Baltimore.

Anderson, S.W., 1995. Measuring the impact of product mix heterogeneity on manufacturing overhead cost. The Accounting Review 70, 363-387.

Arrow, K.J., 1974. The Limits of Organization. Norton, New York.

Ashby, W.R., 1960. Design for a Brain. Wiley, New York.

Banker, R.D., Datar, S.M., Kekre, S., Mukhopadhyay, T., 1990. Costs of Product and Process Complexity. In: Kaplan, R.S. (Ed.), Measures of Manufacturing Excellence. Harvard Business School Press, Boston, pp. 271-290.

Becker, H., 1970. Sociological Work. Aldine, Chicago.

Berry, W., Bozarth, C.C., 1997. Measuring the congruence between market requirements and manufacturing: a methodology and illustration. Decision Sciences 28, 121-150.

Bozarth, C.C., 1993. A conceptual model of manufacturing focus. International Journal of Operations and Production Management 13, 81-92.

Bozarth, C.C., Edwards, S., 1997. The impact of market requirements focus and manufacturing characteristic focus on plant performance. Journal of Operations Management 15, 161-180.

Browne, J., Dubois, D., Rathmill, K., Sethi, S., Stecke, K., 1984. Classification of Flexible Manufacturing Systems. The FMS Magazine, April.

Brush, T., Karnani, A., 1996. Impact of plant size and focus on productivity: an empirical study. Management Science 42, 1065-1081.

Campbell, D.T., 1975. Degrees of freedom and the case study. Comparative Political Studies 8, 178-193.

Cohen, W.M., Levinthal, D.A., 1990. Absorptive capacity: a new perspective on learning and innovation. Administrative Science Quarterly 35, 128-152. 
Cronbach, L., 1975. Beyond the two scientific disciplines of scientific psychology. American Psychologist 30, 116-127.

Diggle, P.J., Liang, K., Zeger, S.L., 1994. Analysis of Longitudinal Data. Oxford Univ. Press, New York.

Donham, W.B., 1922. Essential groundwork for a broad executive theory. Harvard Business Review 1, 1-10.

Durbin, J., Watson, G.S., 1951. Testing for serial correlation in least squares regression. Biometrika 38, 159-177.

Emory, W.C., 1985. Business Research Methods, 3rd edn., R.D. Irwin, Homewood, IL.

Eckstein, H., 1975. Case study and theory in political science. In: Greenstein, F.I., Polsby, N.W. (Eds.), Handbook of Political Science, Vol. VII. Addison-Wesley, Reading, MA, pp. 79-138.

Eisenhardt, K.M., 1989. Building theories from case study research. Academy of Management Review 14, 532-550.

Eisenhardt, K.M., Bourgeois, L.J., 1988. Politics of strategic decision making in high velocity environments: towards a mid-range theory. Academy of Management Journal 31, 737770.

Ferdows, K., 1997. Making the most of foreign factories. Harvard Business Review 75, 73-88.

Foster, G., Gupta, M., 1990. Manufacturing overhead cost driver analysis. Journal of Accounting and Economics 12, 309-338.

Galbraith, J.R., 1977. Organizational Design. Addison Wesley, Reading, MA.

George, A.L., 1979. Case studies and theory development: the method of structured focused comparison. In: Gordon-Lauren, P. (Ed.), Diplomacy: New Approaches in History, Theory, and Politics. The Free Press, New York.

Gerwin, D., 1993. Manufacturing flexibility: a strategic perspective. Management Science 39, 395-410.

Graves, S.C., Jordan, W.H., 1991. Principles on the Benefits of Manufacturing Flexibility, GMR-7310. General Motors Research Laboratories, April.

Harmon, R., 1992. Reinventing the Factory II: Managing the World Class Factory. The Free Press, New York.

Hayes, R., Clark, K.B., 1985. Explaining observed productivity differentials between plants: implications for operations research. Interfaces 15, 3-14.

Hayes, R.H., Schmenner, R.W., 1979. How should you organize manufacturing?. Harvard Business Review 57, 105-118.

Hayes, R., Wheelwright, S.C., 1984. Restoring Our Competitive Edge: Competing through Manufacturing. Wiley, New York.

Hill, T., 1989. Manufacturing Strategy Text and Cases, 1st edn. Irwin, Homewood, Illinois.

Hill, T., 1994. Manufacturing Strategy Text and Cases, 2nd edn. Irwin, Homewood, Illinois.

Hill, A.V., Scudder, G.D., Haugen, D.L., 1987. Production/Operations Management Agenda for the 80's: A Progress Report, In Proceedings of the Annual Meeting. Decision Sciences Institute Annual Meeting, Boston, pp. 840-842.

Hsaio, C., 1985. Analysis of Panel Data. Cambridge Univ. Press, Cambridge, UK.

Juran, J.M., 1979. Quality Control Handbook, 3rd edn. McGraw Hill, New York, NY.

Kaplan, R.S., 1984. Yesterday's accounting undermines production. Harvard Business Review 62, 95-101.
Kekre, S., Srinivasan, K., 1990. Broader product line: a necessity to achieve success?. Management Science 36, 1216-1231.

Kotler, P., 1994. Marketing Management: Analysis, Planning, Implementation and Control, 8th edn. Prentice Hall, Englewood Cliffs, NJ.

Lachenmeyer, C.W., 1971. The Language of Sociology. Columbia Univ. Press, New York.

Lasswell, H.D., 1968. The future of comparative method. Comparative Politics 1, 3-18.

Lijphart, A., 1971. Comparative politics and the comparative method. American Political Science Review 65, 682-693.

Lijphart, A., 1975. The comparable-case strategy in comparative research. Comparative Political Studies 8, 158-177.

March, A., Garvin, D.A., 1986. Copeland : Evolution of a Manufacturing Strategy - 1975-82, HBS Case \#9-686-091. HBS Publishing, Boston, MA.

McDuffie, J.P., Sethuraman, K., Fisher, M.L., 1996. Product variety and manufacturing performance: evidence from the international automotive assembly plant study. Management Science 42, 350-369.

Milgrom, P., Roberts, J., 1990. The economics of modern manufacturing: technology, strategy and organization. American Economic Review 80, 511-528.

Mintzberg, H., McHugh, A., 1985. Strategy formation in an adhocracy. Administrative Science Quarterly 30, 160-197.

Naroll, R., 1962. Data Quality Control: A New Research Technique. The Free Press, New York.

Nelson, R.R., Winter, S., 1982. An Evolutionary Theory of Economic Change. Harvard Univ. Press, Cambridge, MA.

Perrow, C., 1967. Complex Organizations, 3rd edn. Random House, New York, NY.

Perrow, C., 1984. Normal Accidents: Living with High-Risk Technologies. Basic Books, New York, NY.

Pesch, M.J., 1996. Defining and understanding the focused factory: a Delphi survey. Production and Inventory Management Journal 37, 32-36.

Pesch, M.J., Schroeder, R.G., 1996. Measuring factory focus: an empirical study. Production and Operations Management 5, 234.

Prahalad, C.K., Hamel, G., 1990. The Core Competence of the Corporation Harvard Business Review 68, 79-91.

Rommel, G., Kluge, J., Chimps, R., Diederichs, R., Bruck, F., 1995. Simplicity Wins: How Germany's Mid-sized Industrial Companies Succeed. Harvard Business School Press, Boston.

Rosenberg, N., 1982. Inside the Black Box: Technology and Economics. Cambridge Univ. Press, New York.

Russet, B., 1970. International behavior research: case studies and cumulation. In: Haas, M., Kariel, H. (Eds.), Approaches to the Study of Political Science. Chandler, San Francisco, pp. 425443.

Ruwe, D.M., Skinner, W., 1987. Reviving a rust belt factory. Harvard Business Review 65, 70-76.

Scherer, F.M., Ross, D., 1990. Industrial Market Structure and Economic Performance, 3rd edn. Houghton Mifflin, Boston.

Schmenner, R.W., 1982. Multi-plant Manufacturing Strategies among the Fortune 500. Journal of Operations Management, February, 77-86. 
Schmenner, R.W., Swink, M., 1998. On Theory in Operations Management. Journal of Operations Management, forthcoming.

Sethi, A.K., Sethi, S.P., 1990. Flexibility in manufacturing: a survey. International Journal of Flexible Manufacturing Systems 2, 289-328.

Shapiro, R.D., 1985. Toward Effective Supplier Management, HBS Working Paper 9-885-062. Harvard Business School, Boston, MA.

Simon, H.A., 1960. The New Science of Management Decision Making. Harper and Row, New York.

Simon, H.A., 1969. The Sciences of the Artificial. The MIT Press, Cambridge, MA.

Simon, H.A., 1979. Rational decision making in business organizations. American Economic Review 69, 459-474.

Simon, H.A., 1986. Rationality in Psychology and Economics. Journal of Business 59, S209-S224, part 2.

Skinner, W., 1974. The focused factory. Harvard Business Review 52, 113-121.

Stobaugh, R., Telesio, P., 1983. Match manufacturing policies and product strategy. Harvard Business Review 61, 113-119.

Sutton, R., Callahan, A., 1987. The stigma of bankruptcy: spoiled organizational image and its management. Academy of Management Journal 30, 405-436.
Swink, M., Speier, C., 1995. Manufacturing Strategy Research: An Examination of Research Methods and Analytical Techniques. Proceedings of the Decision Sciences Institute Meeting, Boston, November 20-22, 1225-1227.

Tirole, J., 1989. The Theory of Industrial Organization. The MIT Press, Cambridge, MA.

Upton, D.M., 1995. Flexibility as process mobility: the management of plant capabilities for quick response manufacturing. Journal of Operations Management 12, 205-224.

Verba, S., 1976. Some dilemmas in comparative research. World Politics 20, 113-114.

Weick, K.E., 1990. Technology as equivoque: sensemaking in new technologies. In: Goodman, P.S., Sproull, et al., L.S. (Eds.), Technologies and Organizations. Jossey-Bass Publishers, San Francisco, CA, pp. 1-44.

Wernerfelt, B., 1984. A resource-based view of the firm. Strategic Management Journal 5, 171-180.

Wheelwright, S.C., 1979. Facilities Focus: A Study of Concepts and Practices Related to Its Definition, Evaluation, Significance, and Application in Manufacturing Firms, Research Paper \#518. GSB, Stanford University, Stanford, CA.

Yin, R., 1984. Case Study Research. Sage Publications, Beverly Hills, CA. 